\title{
Waves in high-speed plasmoids in the magnetosheath and at the magnetopause
}

\author{
H. Gunell ${ }^{1}$, G. Stenberg Wieser ${ }^{2}$, M. Mella ${ }^{3}$, R. Maggiolo ${ }^{1}$, H. Nilsson ${ }^{2}$, F. Darrouzet ${ }^{1}$, M. Hamrin ${ }^{4}$, T. Karlsson ${ }^{5}$, \\ N. Brenning ${ }^{5}$, J. De Keyser ${ }^{1}$, M. André ${ }^{3}$, and I. Dandouras ${ }^{6}$ \\ ${ }^{1}$ Belgian Institute for Space Aeronomy, Avenue Circulaire 3, 1180 Brussels, Belgium \\ ${ }^{2}$ Swedish Institute of Space Physics (IRF), P.O. Box 812, 98128 Kiruna, Sweden \\ ${ }^{3}$ Swedish Institute of Space Physics (IRF), Box 537, 751 21 Uppsala, Sweden \\ ${ }^{4}$ Department of Physics, Umeå University, 90187 Umeå, Sweden \\ ${ }^{5}$ Space and Plasma Physics, Royal Institute of Technology (KTH), 10044 Stockholm, Sweden \\ ${ }^{6}$ Institut de Recherche en Astrophysique et Planétologie, UPS-CNRS, 31028 Toulouse, France
}

Correspondence to: H. Gunell (herbert.gunell@physics.org)

Received: 29 March 2014 - Revised: 16 June 2014 - Accepted: 11 July 2014 - Published: 22 August 2014

\begin{abstract}
Plasmoids, defined here as plasma entities with a higher anti-sunward velocity component than the surrounding plasma, have been observed in the magnetosheath in recent years. During the month of March 2007 the Cluster spacecraft crossed the magnetopause near the subsolar point 13 times. Plasmoids with larger velocities than the surrounding magnetosheath were found on seven of these 13 occasions. The plasmoids approach the magnetopause and interact with it. Both whistler mode waves and waves in the lower hybrid frequency range appear in these plasmoids, and the energy density of the waves inside the plasmoids is higher than the average wave energy density in the magnetosheath. When the spacecraft are in the magnetosphere, Alfvénic waves are observed. Cold ions of ionospheric origin are seen in connection with these waves, when the wave electric and magnetic fields combine with the Earth's dc magnetic field to yield an $\boldsymbol{E} \times \boldsymbol{B} / B^{2}$ drift speed that is large enough to give the ions energies above the detection threshold.
\end{abstract}

Keywords. Magnetospheric physics (magnetopause, cusp, and boundary layers; magnetosheath) - space plasma physics (wave-particle interactions)

\section{Introduction}

The Earth's magnetosheath is at times a highly structured region, where plasma entities, distinct from the surrounding plasma by either a higher velocity or density or both, have been observed in several studies in the last decade. A few different terms have been used in the literature to denote these plasma entities: for example they were called "MSjets" by Savin et al. (2005), "jets" by Hietala et al. (2009), "supermagnetosonic plasma streams" by Savin et al. (2012), "dynamic pressure enhancements" by Archer and Horbury (2013) and "plasmoids" by Karlsson et al. (2012). We shall use the term "plasmoid" for a plasma entity with higher velocity than the surrounding plasma. This is different from the original usage (Bostick, 1956), but fits within the broader definition "a coherent mass of plasma" in the Oxford English Dictionary (Simpson and Weiner, 1989).

High energy density jets have been observed in the magnetosheath and shown to be deflected towards the magnetopause (Savin et al., 2008). Magnetopause deformation by supermagnetosonic plasma streams has also been reported (Savin et al., 2011). Savin et al. (2012) observed that some of the jets appear in connection with hot flow anomalies, and that there is a significant contribution from supermagnetosonic jets to plasma transport across magnetic boundaries.

Hietala et al. (2009) observed jets in the magnetosheath during a period when the interplanetary magnetic field (IMF) was directed outward from the sun. These jets had speeds a few times above that of the ambient magnetosheath plasma, and it was suggested that their place of origin is at the bow shock. Hietala et al. (2012) expanded these observations and studied their influence on ionospheric convection, and they suggested that local ionospheric flow enhancements were 
caused by plasmoid impact on the magnetopause. Karlsson et al. (2012) studied 56 plasmoids in the magnetosheath, where each had a maximum density at least $50 \%$ above the density of the surrounding plasma. A statistical study of several thousand jets confirmed that these occur during periods with low IMF cone angles - that is to say, when the bow shock is a quasi-parallel shock (Plaschke et al., 2013b) - and showed no significant correlation with other solar wind parameters. Similar results were obtained in another statistical study (Archer and Horbury, 2013).

Hietala and Plaschke (2013) used a model of a magnetohydrodynamic shock to show that ripples on a quasi-parallel bow shock can account for the vast majority of the observed jets, and that other explanations, such as discontinuities in the solar wind, are required only in a few percent of the observed cases.

Shue et al. (2009) observed both sunward and antisunward flows in the magnetosheath near the magnetopause, and it was interpreted as a jet causing an indentation on the magnetopause, which, rebounding, turned the flow back in the sunward direction. Amata et al. (2011) found jets in the magnetosheath making indentations on the magnetopause sunward of the northern cusp. Shue and Chao (2013) showed that a decrease in the magnetic pressure on the inside of the magnetopause is insufficient to explain the inward motion of that boundary and that instead an increased total pressure on the magnetosheath side is required. Gunell et al. (2012) used data from two of the Cluster spacecraft to show that plasmoids, coming from the magnetosheath, penetrated the magnetopause, thus entering the magnetosphere on an occasion when the magnetopause motion was very slow. Magnetopause compression and penetration of magnetosheath plasma into the magnetosphere was found by Dmitriev and Suvorova (2012). The role of three-wave cascades and turbulence in connection with jets and plasma transport at the magnetopause was studied by Savin et al. (2014).

A theory for plasmoids penetrating magnetic barriers was published by Schmidt (1960); it was suggested as a process by which plasma can penetrate the dayside magnetopause by Lemaire (1977); and it has been studied in both laboratory experiments and simulations in the last half century (see for example Wessel et al., 1988; Hurtig et al., 2004; Brenning et al., 2005; Gunell et al., 2008, 2009; Plechaty et al., 2013). Waves, particularly in the lower hybrid frequency range, are reported in those studies, both in the laboratory and in simulations. Such waves have also been observed at the magnetopause (André et al., 2001). Also whistler mode waves have been observed in this part of space, and such waves have been studied extensively in space and laboratory plasmas; see Stenzel (1999) for a review and Stenberg et al. (2007), Tenerani et al. (2013), Watt et al. (2013), Stenzel et al. (2008), or Thuecks et al. (2012) for a few examples of more recent work. Waves are of particular interest in plasma physics, as it is through waves that energy is transferred when discrete particle effects are negligible as a result of Debye shielding.
Furthermore, waves can cause diffusion in collisionless plasmas leading to plasma transport across magnetic fields and to magnetic reconnection (Gekelman and Pfister, 1988).

The generation of Alfvén waves in the magnetosphere by modulation of the solar wind dynamic pressure was studied using a magnetohydrodynamic model (Lysak et al., 1994). The response of the magnetosphere to pressure pulses at the magnetopause was shown to have a low-pass filtering effect (Archer et al., 2013), resulting in magnetospheric oscillations on timescales longer than the duration of any individual plasmoid impact at the magnetopause. The impact of a plasmoid on the magnetopause could alternatively be seen as a wave pulse causing a localised perturbation of that boundary. The transmission of waves from the magnetosheath into the magnetosphere was examined by De Keyser et al. (1999) and De Keyser (2000). Waves enable the transport of energy across the magnetopause, where it can be absorbed in resonant absorption layers (De Keyser and Čadež, 2001a), and enhanced wave amplitudes at the magnetopause can promote diffusive mass transport (De Keyser and Čadež, 2001b).

Plasmoids impacting on the magnetopause cause that boundary to move, and this will also move the plasma in the part of the magnetosphere that is close to the impact site. Sauvaud et al. (2001) observed cold ion populations near the magnetopause. These ions were accelerated by an $\boldsymbol{E} \times \boldsymbol{B}$ drift, which made them visible to the ion spectrometer. Otherwise they are often hidden in the magnetosphere, because their energy is below the threshold for detection. In the presence of Alfvén waves, an $\boldsymbol{E} \times \boldsymbol{B}$ drift in the fields of the wave can bring them to energies above that threshold. Convection and magnetosonic waves can have a similar effect. Hidden cold ion populations can become visible deep in the magnetosphere as a consequence of plasmoids in the magnetosheath that collide with the magnetopause. André et al. (2010) found low-energy ion populations at the magnetopause. André and Cully (2012) surveyed a large part of the magnetosphere, detecting cold $(\mathrm{eV})$ ions in many places, and hypothesised that these are an important part in the escape of ions from the Earth and other planets.

In this work, we examine Cluster data from the month of March 2007. During that month the outbound leg of the Cluster orbit crossed the magnetopause close to the subsolar point on 13 occasions. We find plasmoids with larger velocities than the surrounding magnetosheath approaching the magnetopause from the direction of the bow shock on about half of those days. Section 2 describes how the complete data set is searched for plasmoids, and these are identified and tabulated. The spatial extent of the plasmoids is determined in Sect. 3. In Sect. 4 we examine in more detail two plasmoids that were detected by Cluster 1 on 15 March 2007. One of these was observed at the magnetopause and the other in the magnetosheath. We report on the properties of waves inside these plasmoids, and on cold ions that were seen in the magnetosphere immediately after the plasmoid was detected by the spacecraft. In Sect. 5 it is shown that the energy density 


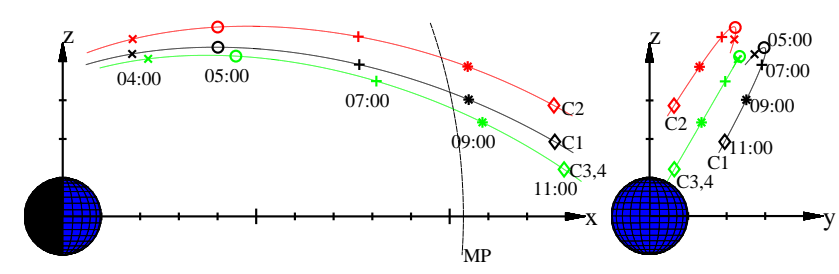

Figure 1. Orbit of Cluster 1 (black), Cluster 2 (red), and Cluster 3 (green) relative to the planet on 15 March 2007. The Cluster 4 spacecraft was very close to Cluster 3 , and the green line therefore represents the orbit of both those spacecraft. The left-hand panel shows the $x-z$ plane in GSE coordinates and the right-hand panel shows the $y-z$ plane. The dashed black curve (marked "MP") in the left panel shows a Shue model magnetopause. Axis unit is $1 R_{\mathrm{E}}$.

of waves in the 10 to $500 \mathrm{~Hz}$ frequency range is higher inside the plasmoids than in the rest of the magnetosheath. In Sect. 6 we report on cold ions that are seen in the magnetosphere in connection with low-frequency waves and examine the relationship between these cold ions in the magnetosphere and plasmoids in the magnetosheath. In Sect. 7 the conclusions are discussed.

\section{Plasmoid observations by Cluster in March 2007}

During the month of March 2007, the Cluster spacecraft crossed the dayside magnetopause 13 times on the outward leg of the orbit. The orbits of Cluster 1, 2 and 3 on 15 March 2007 are illustrated in Fig. 1.

The orbit of Cluster 4 was close enough to that of Cluster 3 that the same curve may represent both spacecraft on the scale shown in the figure. The left-hand panel shows the $x-z$ plane in geocentric solar ecliptic (GSE) coordinates and the right-hand panel shows the $y-z$ plane. We shall use the GSE coordinate system throughout this paper. A Shue model magnetopause (Shue et al., 1997) is shown by the dashed line in the left-hand panel. Figure 1 shows the spacecraft orbits on 15 March 2007, but the geometry is representative for the whole month. The magnetopause is traversed approximately $5 R_{\mathrm{E}}$ (Earth radii) from the subsolar point. We examine Cluster data from all of the 13 magnetopause crossings, restricting the analysis to spacecraft 1 and 3, for which there are data available from the Hot Ion Analyser (HIA) sensor of the Cluster Ion Spectrometry (CIS) instrument (Rème et al., 2001). The HIA sensor measures the ion energy spectrum, but it does not provide mass resolution. The Composition and Distribution Function analyser (CODIF), which is also part of the CIS instrument, does have mass resolution, but in the magnetosheath it often experiences saturation. An example of an outbound magnetopause crossing is shown in Fig. 2.

We have chosen data from Cluster 1 on 17 March 2007 for this illustration. This is the same day that was analysed before by Hietala et al. (2009, 2012). Figure 2a shows the ion velocity measured by the CIS-HIA instrument; Fig. $2 \mathrm{~b}$ shows the magnetic field as measured by the Fluxgate Magnetometer (FGM) (Balogh et al., 2001); and Fig. 2c shows the ion energy spectrum, measured by CIS-HIA. The colour-coded quantity in panel (c) is the logarithm of the omnidirectional differential particle flux, in units of $\mathrm{cm}^{-2} \mathrm{~s}^{-1} \mathrm{sr}^{-1} \mathrm{keV}^{-1}$. At the beginning of the interval shown the spacecraft was in the magnetosphere. Then it moved through a region, where it experienced several magnetopause crossings and being back in the magnetosphere a few times, and finally it reached the magnetosheath. The thick, dashed and solid, lines in Fig. 2 mark the beginning and end, respectively, of this region. The thick dashed line was chosen at the first instant where magnetosheath-like plasma was seen. The magnetosheath plasma is characterised by a lower temperature and a higher density than the plasma in the magnetosphere. The thick solid line represents the time after which no major perturbation was seen in the displayed quantities.

Several short periods can be seen when the observed ion energy spectrum is similar to that in the unperturbed magnetosheath, but where the $x$ component of the velocity is more negative than $v_{x}$ in the magnetosheath - that is to say, where the plasma is moving faster in the anti-sunward direction than the average magnetosheath plasma does. Sometimes, but not always, the excursion in $v_{x}$ is accompanied by similar excursion in $v_{y}$ and $v_{z}$. We shall call these structures plasmoids. We have identified the plasmoids according to the $v_{x}$ component of the ion velocity. The start of each plasmoid is marked by a thin vertical dashed line in Fig. 2, and the end of it is marked by a thin vertical solid line. We have chosen as a selection criterion that the negative peak of the $v_{x}$ component of the plasmoid must be more negative than the $v_{x}$ component of the magnetosheath plasma by a factor of two. Plasmoids are seen both when the spacecraft was in the magnetosheath - for example the one arriving at 19:52:08 UT - and when the spacecraft was at the magnetopause as the plasmoid passed by. An example of the latter situation is the plasmoid that is first seen at 18:49:49. Just before its arrival, both the magnetic field and the ion spectra showed the typical magnetospheric characteristics, which are a strong magnetic field, high temperature and low density.

We have examined Cluster 1 and 3 data from all the 13 outbound orbits during the month and identified plasmoids where such could be found. On seven of these 13 days, namely 1, 5, 8, 15, 17, 24 and 27 March, plasmoids, as described above, were detected. All the plasmoids that have been identified are listed in Table 1. Figures showing the same quantities as Fig. 2, with the identified plasmoids marked, for all outbound magnetopause crossings during March 2007 have been deposited with this article as a Supplement. For comparison, magnetosheath and solar wind data are shown in Table 2. 


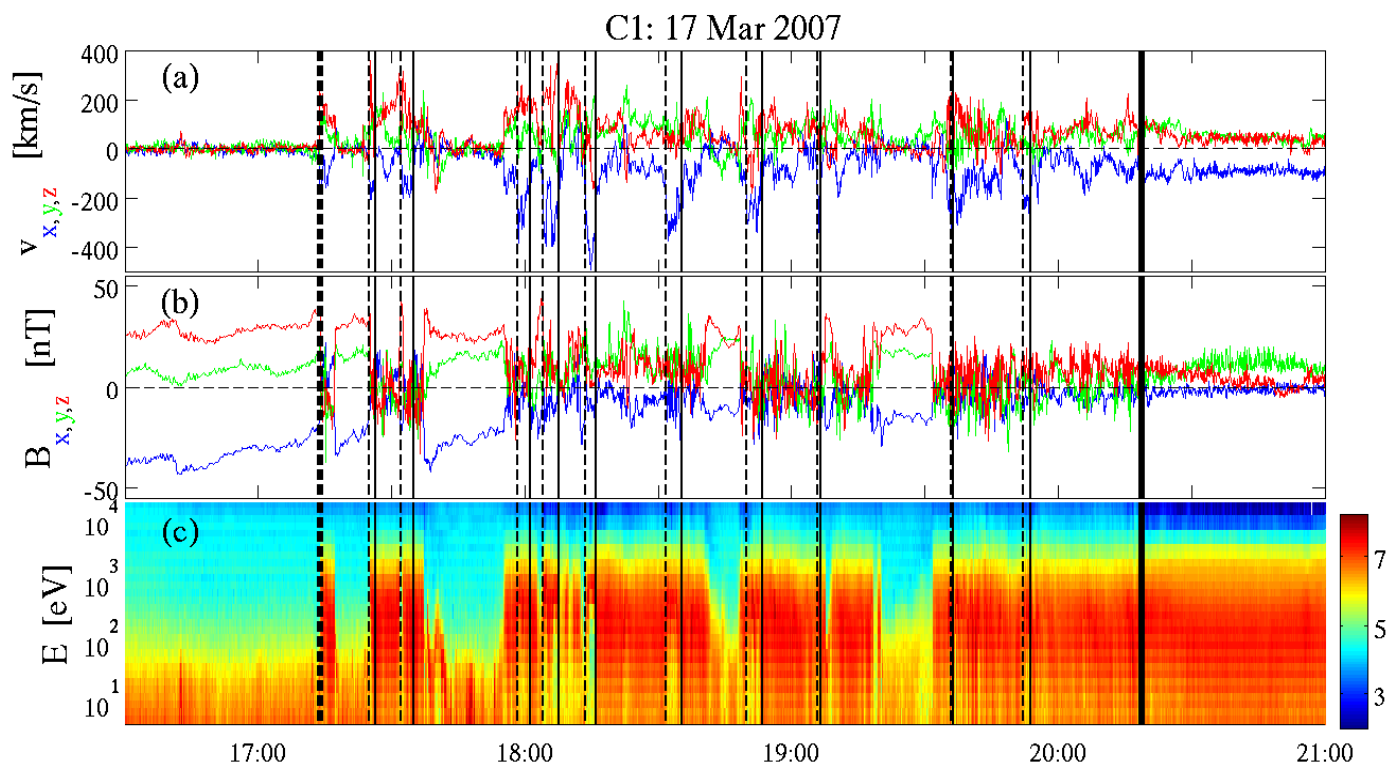

Figure 2. Illustration of plasmoid identification in Cluster 1 data from 17 March 2007. (a) Ion velocity measured by the CIS-HIA instrument. (b) Magnetic flux density measured by the FGM instrument. (c) Omnidirectional ion energy spectrum measured by the CIS-HIA instrument. The colour-coded quantity is the logarithm of the omnidirectional differential particle flux, in units of cm $\mathrm{cm}^{-2} \mathrm{~s}^{-1} \mathrm{sr}^{-1} \mathrm{keV}^{-1}$. The start of each plasmoid is marked by a thin vertical dashed line, and the end of it is marked by a thin vertical solid line. The thick, dashed and solid, lines mark the beginning and end of the region where plasmoids are seen. The velocity and magnetic field are shown in GSE coordinates.

The solar wind speed was measured by the Wind spacecraft, and the tabulated values are the mean values in the interval when the Cluster spacecraft passed through the transition region where plasmoids were observed, as shown by the thick vertical lines in Fig. 2. A delay of $\Delta x(t) / v_{x}(t)$ resulting from the Wind spacecraft being located upstream was taken into account. Here $\Delta x(t)$ denotes the difference between the $x$ coordinates of the Wind and Cluster 1 spacecraft and $v_{x}(t)$ is the $x$ component of the solar wind velocity measured by Wind. The magnetosheath values were measured by Cluster 1 and 3 as indicated, and are mean values of the first 10 minutes each spacecraft spent in the plasmoid-free magnetosheath.

\section{Upper limits of the plasmoid size}

In this paper we attribute certain properties to plasmoids. It is therefore important to show that the observed structures can be classified as such. In addition to the plasma properties discussed in the previous section, one should also require that their size is small enough in comparison with the cross section of the magnetosphere and the thickness of the magnetosheath. If they are larger than the cross section of the magnetosphere, the diameter of which is about $10 R_{\mathrm{E}}$ at the region of the dayside where these observations were made, they should rather be seen as pulses of dynamic pressure in the solar wind. If they are much larger than the thickness of the magnetosheath, which is about $5 R_{\mathrm{E}}$, they would be better described as continuous plasma streams. In this section we examine the spatial extent of the plasmoids by seeking upper limits to the plasmoid size in the direction of the flow and in the direction perpendicular to it. The values we obtain overestimate the plasmoid dimensions, enabling us to establish that the majority of the observed structures are indeed well described by the term plasmoid.

The duration of each plasmoid observation can be used to estimate their size in the direction of the flow. For this purpose the product $T \cdot \max (|v|)$ of the duration and maximum speed values in Table 1 can be used as an upper limit. For the 64 plasmoids in the table, this limit is in a range from $0.5 R_{\mathrm{E}}$ to $20 R_{\mathrm{E}}$ with a median value of $4.9 R_{\mathrm{E}}$, which means that in a majority of cases, the estimated upper limit of the plasmoid size is less than $5 R_{\mathrm{E}}$. It is seen in Fig. $3 \mathrm{~b}$ that there can be large fluctuations in $v_{x}$ within a plasmoid. It is not obvious whether one should consider two negative $v_{x}$ peaks that follow immediately after each other as two separate plasmoids or as being part of a single plasmoid that shows large fluctuations. In such cases, we have counted them as belonging to the same plasmoid. This may affect the size estimate. The preference for larger plasmoids contributes to increasing the estimated size.

To form an estimate in the direction perpendicular to the flow we rely on simultaneous measurements by Cluster 1 and 3. Figure 3 shows data taken by these two spacecraft around 19:00 on 17 March 2007. Panels (a) and (b) show the GSE components of the ion velocity for Cluster 1 and 3 respectively. Panel (c) shows the magnetic field 
Table 1. Plasmoids identified in the data from March 2007. The columns show the first time that the plasmoid was observed; its duration $T$; the spacecraft that observed it; the maximum value of the plasma speed, $\max (|v|)$, within the plasmoid; the most negative $v_{x}$ value; the maximum density $\max (n)$; and the mean energy density of the magnetic $\left\langle P_{\mathrm{BB}} / \mu_{0}\right\rangle$ and electric $\left\langle\epsilon_{0} P_{\mathrm{EE}}\right\rangle$ fluctuations in the frequency range $10 \mathrm{~Hz} \leq f \leq 500 \mathrm{~Hz}$, measured by the STAFF instrument.

\begin{tabular}{|c|c|c|c|c|c|c|c|}
\hline Start & $\begin{array}{l}T \\
(\mathrm{~s})\end{array}$ & $s / c$ & $\begin{array}{l}\max (|v|) \\
\left(\mathrm{km} \mathrm{s}^{-1}\right)\end{array}$ & $\begin{array}{l}\min \left(v_{x}\right) \\
\left(\mathrm{km} \mathrm{s}^{-1}\right)\end{array}$ & $\begin{array}{c}\max (n) \\
\left(\mathrm{m}^{-3}\right)\end{array}$ & $\begin{array}{c}\left\langle P_{\mathrm{BB}} / \mu_{0}\right\rangle \\
\left(\mathrm{J} \mathrm{m}^{-3}\right)\end{array}$ & $\begin{array}{l}\left\langle\epsilon_{0} P_{\mathrm{EE}}\right\rangle \\
\left(\mathrm{J} \mathrm{m}^{-3}\right)\end{array}$ \\
\hline 2007-03-01 02:55:56 & 41 & C3 & 334 & -334 & $2.0 \times 10^{7}$ & $1.9 \times 10^{-14}$ & $3.5 \times 10^{-19}$ \\
\hline 2007-03-01 02:56:09 & 100 & $\mathrm{C} 1$ & 359 & -354 & $2.3 \times 10^{7}$ & $1.8 \times 10^{-14}$ & $9.1 \times 10^{-19}$ \\
\hline 2007-03-01 03:10:00 & 309 & $\mathrm{C} 3$ & 335 & -289 & $2.3 \times 10^{7}$ & $3.7 \times 10^{-15}$ & $1.4 \times 10^{-19}$ \\
\hline 2007-03-01 03:10:49 & 174 & $\mathrm{C} 1$ & 410 & -386 & $2.1 \times 10^{7}$ & $7.3 \times 10^{-15}$ & $1.7 \times 10^{-19}$ \\
\hline 2007-03-01 03:58:49 & 203 & $\mathrm{C} 3$ & 403 & -369 & $3.5 \times 10^{7}$ & $1.6 \times 10^{-14}$ & $1.3 \times 10^{-18}$ \\
\hline 2007-03-01 04:01:04 & 137 & $\mathrm{C} 1$ & 394 & -380 & $1.8 \times 10^{7}$ & $1.8 \times 10^{-14}$ & $1.3 \times 10^{-18}$ \\
\hline 2007-03-01 04:09:59 & 78 & $\mathrm{C} 3$ & 470 & -440 & $2.1 \times 10^{7}$ & $3.6 \times 10^{-14}$ & $2.5 \times 10^{-18}$ \\
\hline 2007-03-01 04:11:18 & 29 & $\mathrm{C} 1$ & 434 & -402 & $2.3 \times 10^{7}$ & $1.3 \times 10^{-13}$ & $3.8 \times 10^{-18}$ \\
\hline 2007-03-01 04:22:58 & 76 & $\mathrm{C} 3$ & 370 & -327 & $1.4 \times 10^{7}$ & $3.2 \times 10^{-15}$ & $1.2 \times 10^{-19}$ \\
\hline 2007-03-05 18:53:21 & 93 & $\mathrm{C} 1$ & 435 & -318 & $1.8 \times 10^{7}$ & $3.8 \times 10^{-13}$ & $3.0 \times 10^{-17}$ \\
\hline 2007-03-05 18:53:30 & 45 & $\mathrm{C} 3$ & 247 & -158 & $2.4 \times 10^{7}$ & $4.2 \times 10^{-14}$ & $4.2 \times 10^{-17}$ \\
\hline 2007-03-05 18:55:14 & 313 & $\mathrm{C} 1$ & 349 & -238 & $2.7 \times 10^{7}$ & $2.1 \times 10^{-13}$ & $3.3 \times 10^{-17}$ \\
\hline 2007-03-05 18:56:23 & 144 & $\mathrm{C} 3$ & 368 & -208 & $3.3 \times 10^{7}$ & $1.3 \times 10^{-13}$ & $4.7 \times 10^{-17}$ \\
\hline 2007-03-05 18:59:04 & 79 & $\mathrm{C} 3$ & 348 & -200 & $3.4 \times 10^{7}$ & $3.4 \times 10^{-13}$ & $3.2 \times 10^{-17}$ \\
\hline 2007-03-05 19:02:02 & 21 & $\mathrm{C} 3$ & 277 & -145 & $3.0 \times 10^{7}$ & $3.9 \times 10^{-13}$ & $3.7 \times 10^{-17}$ \\
\hline 2007-03-05 19:02:14 & 25 & $\mathrm{C} 1$ & 253 & -176 & $2.4 \times 10^{7}$ & $2.3 \times 10^{-13}$ & $1.1 \times 10^{-17}$ \\
\hline 2007-03-05 19:07:57 & 282 & $\mathrm{C} 1$ & 363 & -247 & $2.2 \times 10^{7}$ & $9.2 \times 10^{-14}$ & $3.7 \times 10^{-17}$ \\
\hline 2007-03-05 19:12:02 & 24 & $\mathrm{C} 3$ & 446 & -298 & $1.6 \times 10^{6}$ & $2.1 \times 10^{-16}$ & $1.0 \times 10^{-17}$ \\
\hline 2007-03-05 19:15:16 & 91 & $\mathrm{C} 3$ & 418 & -231 & $1.9 \times 10^{7}$ & $3.0 \times 10^{-13}$ & $7.4 \times 10^{-17}$ \\
\hline 2007-03-05 19:16:10 & 67 & $\mathrm{C} 1$ & 306 & -183 & $2.4 \times 10^{7}$ & $1.1 \times 10^{-13}$ & $4.1 \times 10^{-17}$ \\
\hline 2007-03-08 07:44:51 & 148 & $\mathrm{C} 3$ & 106 & -93 & $6.6 \times 10^{6}$ & $4.8 \times 10^{-16}$ & $1.5 \times 10^{-19}$ \\
\hline 2007-03-08 09:03:10 & 128 & $\mathrm{C} 3$ & 196 & -130 & $9.0 \times 10^{6}$ & $2.1 \times 10^{-15}$ & $3.3 \times 10^{-20}$ \\
\hline 2007-03-15 08:00:39 & 159 & $\mathrm{C} 1$ & 404 & -394 & $2.1 \times 10^{7}$ & $3.0 \times 10^{-13}$ & $7.0 \times 10^{-17}$ \\
\hline 2007-03-15 08:09:01 & 58 & $\mathrm{C} 1$ & 521 & -468 & $1.2 \times 10^{7}$ & $3.9 \times 10^{-13}$ & $1.7 \times 10^{-17}$ \\
\hline 2007-03-15 09:32:57 & 37 & $\mathrm{C} 1$ & 368 & -336 & $1.1 \times 10^{7}$ & $1.3 \times 10^{-13}$ & $1.7 \times 10^{-17}$ \\
\hline 2007-03-15 09:53:58 & 21 & $\mathrm{C} 1$ & 514 & -504 & $1.3 \times 10^{7}$ & $2.1 \times 10^{-13}$ & $7.8 \times 10^{-18}$ \\
\hline 2007-03-15 09:55:09 & 104 & $\mathrm{C} 1$ & 587 & -523 & $2.1 \times 10^{7}$ & $4.7 \times 10^{-13}$ & $2.9 \times 10^{-17}$ \\
\hline 2007-03-15 10:14:59 & 71 & $\mathrm{C} 1$ & 526 & -514 & $1.3 \times 10^{7}$ & $1.1 \times 10^{-12}$ & $1.5 \times 10^{-16}$ \\
\hline 2007-03-15 10:21:05 & 29 & $\mathrm{C} 1$ & 444 & -441 & & $8.4 \times 10^{-13}$ & $9.2 \times 10^{-17}$ \\
\hline 2007-03-15 10:23:26 & 20 & $\mathrm{C} 1$ & 542 & -503 & $8.2 \times 10^{6}$ & $1.1 \times 10^{-12}$ & $1.0 \times 10^{-16}$ \\
\hline 2007-03-17 17:24:58 & 50 & $\mathrm{C} 3$ & 425 & -306 & $2.0 \times 10^{7}$ & $1.0 \times 10^{-14}$ & $7.5 \times 10^{-18}$ \\
\hline 2007-03-17 17:25:04 & 74 & $\mathrm{C} 1$ & 424 & -206 & $2.5 \times 10^{7}$ & $1.2 \times 10^{-14}$ & $5.4 \times 10^{-18}$ \\
\hline 2007-03-17 17:31:23 & 272 & $\mathrm{C} 3$ & 383 & -321 & $2.3 \times 10^{7}$ & $5.7 \times 10^{-15}$ & $3.9 \times 10^{-19}$ \\
\hline 2007-03-17 17:32:15 & 166 & $\mathrm{C} 1$ & 394 & -199 & $2.2 \times 10^{7}$ & $5.3 \times 10^{-15}$ & $4.6 \times 10^{-19}$ \\
\hline 2007-03-17 17:56:19 & 74 & $\mathrm{C} 3$ & 336 & -234 & $1.8 \times 10^{7}$ & $2.7 \times 10^{-15}$ & $5.8 \times 10^{-18}$ \\
\hline 2007-03-17 17:58:24 & 165 & $\mathrm{C} 1$ & 415 & -383 & $1.9 \times 10^{7}$ & $2.9 \times 10^{-15}$ & $1.9 \times 10^{-19}$ \\
\hline 2007-03-17 17:58:39 & 108 & $\mathrm{C} 3$ & 335 & -329 & $1.3 \times 10^{7}$ & $2.7 \times 10^{-15}$ & $1.3 \times 10^{-19}$ \\
\hline 2007-03-17 18:04:02 & 177 & $\mathrm{C} 3$ & 449 & -438 & $3.2 \times 10^{7}$ & $7.4 \times 10^{-15}$ & $9.4 \times 10^{-19}$ \\
\hline 2007-03-17 18:04:12 & 203 & $\mathrm{C} 1$ & 464 & -395 & $2.8 \times 10^{7}$ & $1.1 \times 10^{-14}$ & $4.8 \times 10^{-19}$ \\
\hline 2007-03-17 18:13:24 & 231 & $\mathrm{C} 3$ & 499 & -491 & $2.4 \times 10^{7}$ & $8.9 \times 10^{-15}$ & $1.7 \times 10^{-18}$ \\
\hline 2007-03-17 18:13:36 & 150 & $\mathrm{C} 1$ & 498 & -493 & $1.9 \times 10^{7}$ & $1.3 \times 10^{-14}$ & $8.9 \times 10^{-19}$ \\
\hline 2007-03-17 18:31:31 & 260 & $\mathrm{C} 3$ & 475 & -450 & $1.8 \times 10^{7}$ & $2.3 \times 10^{-15}$ & $6.6 \times 10^{-19}$ \\
\hline 2007-03-17 18:31:52 & 215 & $\mathrm{C} 1$ & 386 & -372 & $2.0 \times 10^{7}$ & $4.5 \times 10^{-15}$ & $1.2 \times 10^{-18}$ \\
\hline 2007-03-17 18:49:49 & 217 & $\mathrm{C} 1$ & 361 & -340 & $1.8 \times 10^{7}$ & $4.7 \times 10^{-15}$ & $2.0 \times 10^{-18}$ \\
\hline 2007-03-17 18:50:32 & 74 & $\mathrm{C} 3$ & 331 & -289 & $1.9 \times 10^{7}$ & $3.7 \times 10^{-15}$ & $5.4 \times 10^{-19}$ \\
\hline 2007-03-17 18:53:46 & 116 & $\mathrm{C} 3$ & 295 & -293 & $2.5 \times 10^{7}$ & $1.1 \times 10^{-14}$ & $1.8 \times 10^{-18}$ \\
\hline 2007-03-17 19:02:47 & 124 & $\mathrm{C} 3$ & 330 & -303 & $1.5 \times 10^{7}$ & $3.5 \times 10^{-15}$ & $8.5 \times 10^{-19}$ \\
\hline 2007-03-17 19:05:57 & 33 & $\mathrm{C} 1$ & 375 & -364 & $1.5 \times 10^{7}$ & $3.4 \times 10^{-15}$ & $3.9 \times 10^{-19}$ \\
\hline 2007-03-17 19:34:54 & 70 & $\mathrm{C} 3$ & 457 & -405 & $1.6 \times 10^{7}$ & $3.0 \times 10^{-15}$ & $1.5 \times 10^{-18}$ \\
\hline 2007-03-17 19:35:53 & 25 & $\mathrm{C} 1$ & 424 & -376 & $1.5 \times 10^{7}$ & $2.2 \times 10^{-15}$ & $2.7 \times 10^{-19}$ \\
\hline 2007-03-17 19:52:08 & 100 & $\mathrm{C} 1$ & 373 & -345 & $1.7 \times 10^{7}$ & $3.1 \times 10^{-15}$ & $2.1 \times 10^{-19}$ \\
\hline 2007-03-17 19:52:32 & 95 & $\mathrm{C} 3$ & 480 & -458 & $1.8 \times 10^{7}$ & $6.0 \times 10^{-15}$ & $1.7 \times 10^{-18}$ \\
\hline 2007-03-17 20:14:39 & 57 & $\mathrm{C} 3$ & 320 & -183 & $1.5 \times 10^{7}$ & $1.6 \times 10^{-15}$ & $1.5 \times 10^{-19}$ \\
\hline 2007-03-24 19:09:55 & 33 & $\mathrm{C} 3$ & 106 & -86.4 & $2.1 \times 10^{6}$ & $1.0 \times 10^{-17}$ & $3.5 \times 10^{-18}$ \\
\hline 2007-03-24 19:35:13 & 162 & $\mathrm{C} 1$ & 392 & -212 & $3.8 \times 10^{7}$ & $4.5 \times 10^{-15}$ & $2.0 \times 10^{-17}$ \\
\hline 2007-03-24 19:37:20 & 33 & $\mathrm{C} 3$ & 299 & -130 & $1.7 \times 10^{7}$ & $5.1 \times 10^{-16}$ & $2.0 \times 10^{-17}$ \\
\hline 2007-03-24 20:01:26 & 29 & $\mathrm{C} 1$ & 173 & -151 & $1.3 \times 10^{7}$ & $2.3 \times 10^{-16}$ & $4.7 \times 10^{-17}$ \\
\hline 2007-03-24 20:04:28 & 104 & $\mathrm{C} 1$ & 214 & -171 & $2.5 \times 10^{7}$ & $1.3 \times 10^{-15}$ & $4.6 \times 10^{-18}$ \\
\hline 2007-03-24 20:07:18 & 87 & $\mathrm{C} 3$ & 244 & -160 & $1.5 \times 10^{7}$ & $3.9 \times 10^{-16}$ & $1.3 \times 10^{-17}$ \\
\hline 2007-03-27 05:07:03 & 66 & $\mathrm{C} 1$ & 479 & -195 & $2.0 \times 10^{7}$ & $7.5 \times 10^{-15}$ & $9.1 \times 10^{-17}$ \\
\hline 2007-03-27 05:57:37 & 98 & $\mathrm{C} 3$ & 190 & -179 & $5.0 \times 10^{7}$ & $10.0 \times 10^{-15}$ & $1.8 \times 10^{-19}$ \\
\hline 2007-03-27 06:00:50 & 136 & $\mathrm{C} 3$ & 200 & -189 & $6.2 \times 10^{7}$ & $1.2 \times 10^{-14}$ & $1.3 \times 10^{-18}$ \\
\hline 2007-03-27 06:07:35 & 99 & $\mathrm{C} 3$ & 203 & -179 & $4.9 \times 10^{7}$ & $1.5 \times 10^{-14}$ & $6.3 \times 10^{-19}$ \\
\hline 2007-03-27 06:13:22 & 54 & $\mathrm{C} 1$ & 197 & -190 & $6.0 \times 10^{7}$ & $1.6 \times 10^{-14}$ & $1.2 \times 10^{-18}$ \\
\hline 2007-03-27 06:15:14 & 111 & $\mathrm{C} 3$ & 286 & -262 & $3.9 \times 10^{7}$ & $1.1 \times 10^{-14}$ & $1.1 \times 10^{-18}$ \\
\hline
\end{tabular}




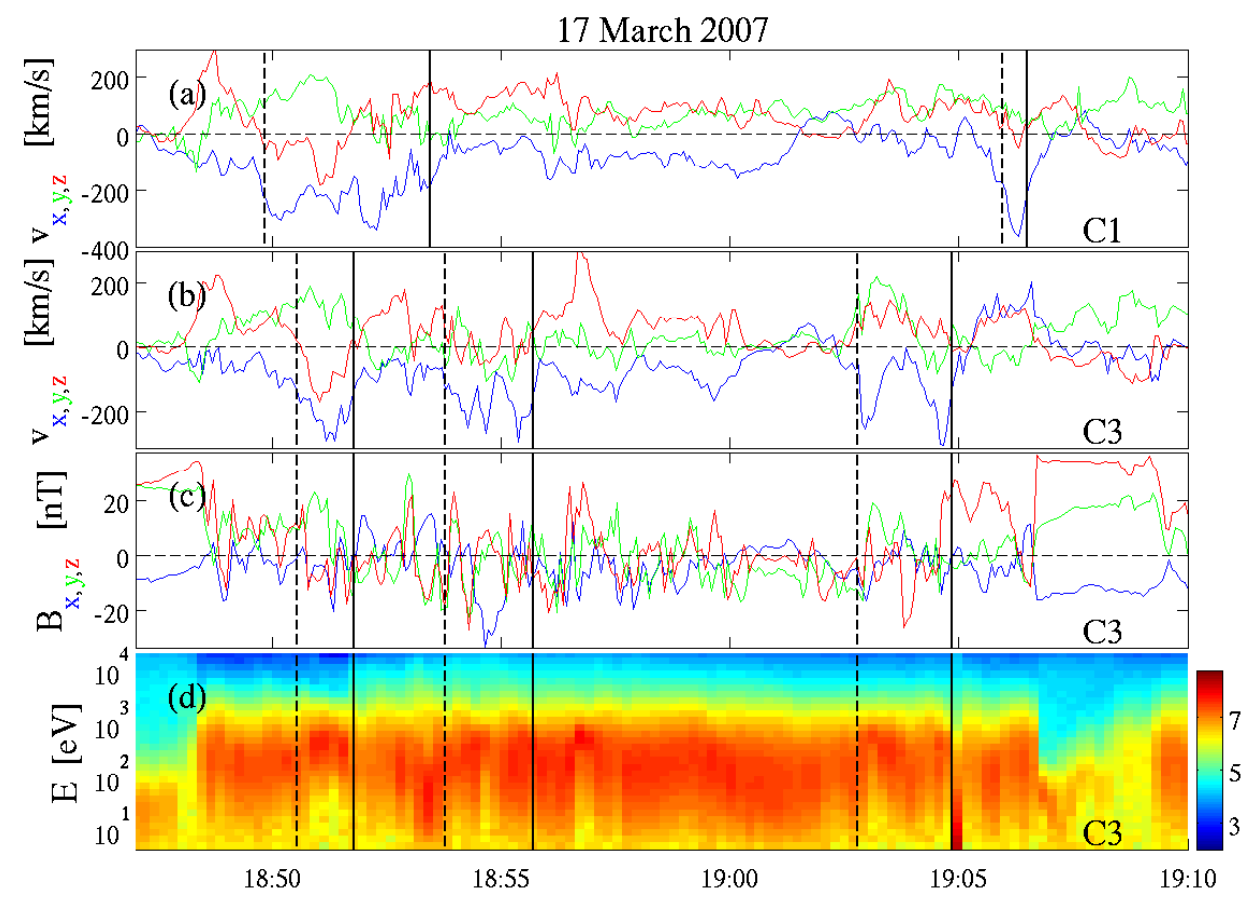

Figure 3. Comparison of data from Cluster 1 and 3 on 17 March 2007. (a) Ion velocity components in GSE coordinates for Cluster 1. (b) Ion velocity for Cluster 3. (c) Magnetic flux density for Cluster 3. (d) Omnidirectional ion energy spectrum. The colour coded quantity is the logarithm of the omnidirectional differential particle flux, in units of $\mathrm{cm}^{-2} \mathrm{~s}^{-1} \mathrm{sr}^{-1} \mathrm{keV}^{-1}$. The start of each plasmoid is marked by a vertical dashed line, and the end of it is marked by a vertical solid line. For Cluster 1 these quantities are shown for a longer period in Fig. 2

and panel (d) the omnidirectional ion energy spectrum observed by Cluster 3. The magnetic field and ion energy spectrum for Cluster 1 is shown in Fig. 2, although on a different timescale. The vertical dashed and solid lines mark the beginning and end, respectively, of each identified plasmoid during the period shown. This example has been chosen because both spacecraft were in the magnetosheath, as is seen from the magnetic field and ion spectra, and therefore estimate is not influenced by the response of the magnetopause to the plasmoid impact. At 19:00 the position of Cluster 1 was $\boldsymbol{r}_{\mathrm{C} 1}=(11.6 ; 1.8 ; 2.5) R_{\mathrm{E}}$ and that of Cluster $3 \boldsymbol{r}_{\mathrm{C} 3}=(11.9 ; 0.55 ; 1.9) R_{\mathrm{E}}$, and the resulting spacecraft separation was $\boldsymbol{r}_{\mathrm{C} 1}-\boldsymbol{r}_{\mathrm{C} 3}=(-1755 ; 7999 ; 4212) \mathrm{km}$. With this separation, and the $v_{x}$ values in the plasmoids, a structure of large spatial extent in the direction perpendicular to the $x$ axis would first be seen at Cluster 3 and then at Cluster 1 after about 5-9s. It is possible that the first plasmoid seen by Cluster 1 in Fig. 3a is the same one that was seen by Cluster 3, which then passed through a smaller part of it. It is also possible that the two spacecraft observed two different plasmoids. Short of having a large number of spacecraft lined up between Cluster 1 and 3 this is impossible to determine, as plasma properties are likely to vary between different parts of the same plasmoid. The two later plasmoids seen by Cluster 3 are not seen by Cluster 1, and the last one seen by Cluster 1 is not seen by Cluster 3 . The delay between the last plasmoids for each spacecraft in the figure is more than a minute, which is much more than the 5-9s that would be expected under the assumption of a large perpendicular extent.

During the days when data from the CIS-HIA instruments on both Cluster 1 and Cluster 3 were available 24 plasmoids were seen by Cluster 1 and 31 by Cluster 3 . Of the 24 plasmoids that Cluster 1 observed, 18 overlapped completely or partially with plasmoids seen by Cluster 3 , using the plasmoid durations in Table 1. If we allow for a $30 \mathrm{~s}$ delay between the spacecraft, a time confidently longer than the 5$9 \mathrm{~s}$ cited above, this number increases to 19 . Taking care not to underestimate the plasmoid size, we count overlapping observations by the two spacecraft as both of these having observed one and the same plasmoid. This means that we probably overestimate the plasmoid size, as it is likely that in some of the cases the two spacecraft each observed different individual plasmoids.

Given that the spacecraft separation in a plane perpendicular to the $x$ axis was $S=1.4 R_{\mathrm{E}}$, one may estimate the perpendicular extent of the plasmoids. This was done by assuming plasmoids of circular cross section in the plane perpendicular to the $x$ axis that are positioned at random in that plane. The method is illustrated in Fig. 4. The plasmoid is shown by the large black circle with radius $R$. If Cluster 1 is in the green area, Cluster 3 is also inside the plasmoid, and if Cluster 1 is in the white crescent-shaped region, Cluster 3 is outside of the plasmoid. The probability $p_{\mathrm{A}}$ that both spacecraft see the plasmoid, given that Cluster 1 does, is the ratio 


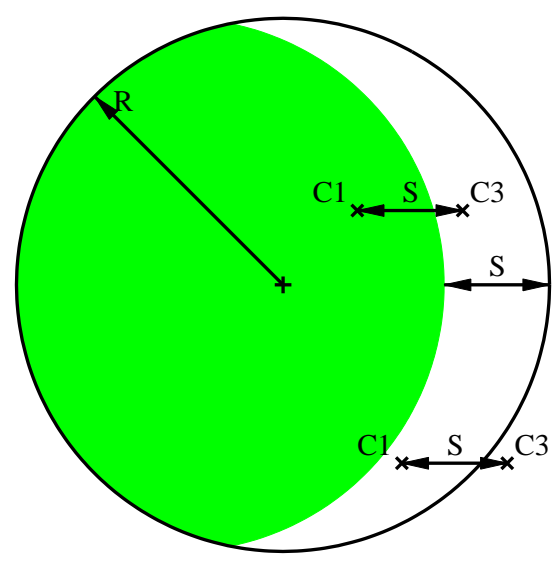

Figure 4. Illustration of the method by which the perpendicular plasmoid extent is estimated. The plasmoid is shown by the large black circle with radius $R$. If Cluster 1 is in the green area, Cluster 3 is also inside the plasmoid. If Cluster 1 is in the white crescentshaped area, Cluster 3 is outside the plasmoid. The spacecraft positions, marked " $x$ ", show examples of the two situations.

of the green area to the total area of the circle:

$p_{\mathrm{A}}=\frac{2 R^{2} \arccos \left(\frac{S}{2 R}\right)-\frac{S}{2} \sqrt{4 R^{2}-S^{2}}}{\pi R^{2}}$.

If 18 of the 24 plasmoids observed at Cluster 1 also were observed by the other spacecraft, we have $p_{\mathrm{A}}=0.75$, assuming that we observed the most likely outcome. Solving Eq. (1) numerically with $p_{\mathrm{A}}=0.75$ and $S=1.4 R_{\mathrm{E}}$, we obtain $R=3.6 R_{\mathrm{E}}$, which we take as an order of magnitude estimate of the perpendicular extent. With the same numbers reported above one could use the 31 plasmoids seen by Cluster 3 and the 18 simultaneous observations to obtain $p_{\mathrm{A}}=18 / 31 \approx 0.58$, which corresponds to $R=2.1 R_{\mathrm{E}}$. As we are looking for an upper limit we shall use the higher value of $R=3.6 R_{\mathrm{E}}$.

The conclusion of this section is that the plasma entities considered can be described as plasmoids. The estimated plasmoid radius of $R=3.6 R_{\mathrm{E}}$ corresponds to a diameter of $7.2 R_{\mathrm{E}}$, which is below the diameter of the magnetopause at the part of the dayside where the observations were made, which is about $R=10 R_{\mathrm{E}}$. The plasmoid description is thus more suitable than that of a solar wind dynamic pressure pulse. As we are overestimating the size, the majority of the plasmoids are smaller than $7 R_{\mathrm{E}}$. The median value of the plasmoid extent in the direction of the plasma flow is $R=4.9 R_{\mathrm{E}}$, which is approximately the same as the thickness of the magnetosheath. This means that at least half of the plasmoids should at some instant in time be detached from both the bow shock and the magnetopause. To make the opposite interpretation, namely that of a continuous plasma stream, one should require a plasmoid that is much larger than the magnetosheath thickness.
In the direction along the plasma flow, Němeček et al. (1998) found that the dimensions of the plasmoids they observed were "in the range of units of $R_{\mathrm{E}}$ "; Plaschke et al. (2013b) estimated the median extent to $4000 \mathrm{~km}$, and the dimensions found by Archer et al. (2012) were approximately $1 R_{\mathrm{E}}$. Considering that we overestimate the parallel dimension by using the maximum plasma speed inside the plasmoid instead of integrating the velocity, our estimate is not in disagreement with the previous authors.

In the direction perpendicular to the flow, Archer et al. (2012) estimated the spatial dimensions from the spacecraft separation without considering what fraction of the plasmoids were observed by both spacecraft. Their estimate of $0.2-0.5 R_{\mathrm{E}}$ is therefore likely an underestimate. Our value of a $3.6 R_{\mathrm{E}}$ radius is an overestimate, and the true value should be in between. However, there is a wide spread in the distribution of sizes, as was shown by Karlsson et al. (2012), who observed a size range spanning from $0.1 R_{\mathrm{E}}$ to $10 R_{\mathrm{E}}$.

\section{Details of two plasmoids}

We examine two plasmoids that were observed at the magnetopause and in the magnetosheath respectively on 15 March 2007. On this date CIS-HIA data were not available for Cluster 3. Therefore, the study of these particular plasmoids is limited to a single spacecraft. Figure 5 shows a summary of the data obtained by Wind and Cluster 1 on 15 March 2007. The Wind spacecraft was located at $(x, y, z)=(199,-42,-18) R_{\mathrm{E}}$, which means that it takes the plasma about 31 minutes to move from the Wind spacecraft to the position of the Cluster spacecraft. This delay has been taken into account in Fig. 5, showing all data on the Cluster 1 time base, which means that the time plotted in panels (a) and (b) is $t_{\mathrm{C} 1}=t_{\mathrm{W}}+\Delta x\left(t_{\mathrm{W}}\right) / v_{x}\left(t_{\mathrm{W}}\right)$, where $t_{\mathrm{W}}$ is the wind time base, $\Delta x\left(t_{\mathrm{W}}\right)$ denotes the difference between the $x$ coordinates of the Wind and Cluster 1 spacecraft and $v_{x}\left(t_{\mathrm{W}}\right)$ is the $x$ component of the solar wind velocity measured by Wind. Panel (a) shows the solar wind magnetic field and panel (b) shows the solar wind dynamic pressure, both measured by Wind. Panel (c) shows the magnetic field measured by the FGM instrument on Cluster 1. Panel (d) shows the bulk velocity of the ions and panel (e) the ion density, both measured by CIS-HIA. Panel (f) shows the electron energy spectrum measured by the Plasma Electron and Current Experiment (PEACE) instrument (Johnstone et al., 1997) for energies above $1 \mathrm{keV}$. The colour-coded quantity is the logarithm of the omnidirectional differential particle flux, in units of $\mathrm{cm}^{-2} \mathrm{~s}^{-1} \mathrm{sr}^{-1} \mathrm{keV}^{-1}$. Finally, panel (g) of Fig. 5 shows the ion energy spectrum measured by CIS-HIA. Like in the case of the electron spectrum, the colour-coded quantity is the logarithm of the omnidirectional differential particle flux, in units of $\mathrm{cm}^{-2} \mathrm{~s}^{-1} \mathrm{sr}^{-1} \mathrm{keV}^{-1}$. The magnitude of the solar wind magnetic field showed only small variations, although its direction varied during the period in question. Also the 
Table 2. Magnetosheath and solar wind data. The solar wind speed and magnetic field were measured by the Wind spacecraft. The magnetosheath values are mean values of the first 10 min Cluster 1 and 3, respectively, spent in the magnetosheath after the last plasmoid was seen.

\begin{tabular}{|c|c|c|c|c|c|}
\hline \multirow[t]{2}{*}{ Date } & \multirow{2}{*}{$\begin{array}{r}\left|v_{\mathrm{SW}}\right| \\
\left(\mathrm{km} \mathrm{s}^{-1}\right)\end{array}$} & \multicolumn{2}{|c|}{$\left|v_{\mathrm{MS}}\right|$} & \multicolumn{2}{|c|}{$\boldsymbol{B}_{\mathrm{MS}}$} \\
\hline & & $\begin{array}{r}\mathrm{C} 1 \\
\left(\mathrm{~km} \mathrm{~s}^{-1}\right)\end{array}$ & $\begin{array}{r}\mathrm{C} 3 \\
\left(\mathrm{~km} \mathrm{~s}^{-1}\right)\end{array}$ & $\begin{array}{l}\text { C1 } \\
(\mathrm{nT})\end{array}$ & $\begin{array}{l}\mathrm{C} 3 \\
(\mathrm{nT})\end{array}$ \\
\hline 2007-03-01 & 610 & 180 & 168 & $(-2.4,12,8.5)$ & $(-3.4,13,-7.8)$ \\
\hline 2007-03-03 & 358 & 74 & 58 & $(-11,15,26)$ & $(-7.6,16,26)$ \\
\hline 2007-03-05 & 393 & 116 & 101 & $(12,-13,-21)$ & $(13,-16,-26)$ \\
\hline 2007-03-08 & 475 & - & 67 & $(1.5,-13,3.6)$ & $(0.91,-13,3.6)$ \\
\hline 2007-03-10 & 343 & 125 & 100 & $(8.5,-25,-6.0)$ & $(7.3,-28,-7.2)$ \\
\hline 2007-03-12 & 601 & 191 & 154 & $(-4.6,32,-16)$ & $(-2.7,33,-17)$ \\
\hline 2007-03-15 & 637 & 180 & - & $(-0.72,10,-6.3)$ & $(-0.5,10,-5.8)$ \\
\hline 2007-03-17 & 535 & 148 & 102 & $(-2.3,5.6,9.0)$ & $(-0.89,9.6,7)$ \\
\hline 2007-03-20 & 344 & 54 & 41 & $(-0.58,17,-2.9)$ & $(1.1,17,-3.2)$ \\
\hline $2007-03-22$ & 269 & 64 & 55 & $(3.3,-23,-7.7)$ & $(1.8,-25,-7.5)$ \\
\hline 2007-03-24 & 350 & 113 & 73 & $(-19,-24,54)$ & $(-18,-17,61)$ \\
\hline $2007-03-27$ & 447 & 93 & 76 & $(-3.5,31,4.9)$ & $(-0.37,30,3.8)$ \\
\hline $2007-03-29$ & 397 & 86 & 66 & $(-0.066,25,-3.1)$ & $(1.5,21,-2.3)$ \\
\hline
\end{tabular}

solar wind dynamic pressure was relatively constant. The Dst and Kp indices showed a moderate geomagnetic activity. Throughout 15 March Dst was above $-20 \mathrm{nT}$, and its mean value between midnight and noon was $-11.75 \mathrm{nT}$. The Kp index was $2+$ from 03:00 to 06:00; 3 - between 06:00 and 09:00; and 2 from 09:00 to 12:00.

At the start of the interval shown in Fig. 5 the spacecraft is inside the magnetosphere, and as it moves outward it reaches the magnetopause at 08:00:39 UT. This is when we have identified the first plasmoid. After the passage of the plasmoid, the spacecraft found itself in the magnetosphere again and stayed there until the arrival of the next plasmoid at 08:09:01. In the period between the second plasmoid observation and 08:30 a few magnetopause crossings were seen that did not coincide with plasmoid detections. After that time the spacecraft was in the magnetosheath, away from the magnetopause. There, several plasmoids were observed until about 10:30, and after this time no plasmoids were seen.

Apart from the defining feature of the plasmoids, that is to say, that the $v_{x}$ component of the velocity (Fig. $5 \mathrm{~d}$ ) reaches a large negative value, we see that the density increases from the low levels of the magnetosphere to a level of the order of the magnetosheath density for those plasmoids that are observed at the magnetopause. For those that were observed in the magnetosheath, farther away from the magnetopause, the density is already at magnetosheath levels and, while a relative increase can be seen at some plasmoids it is less conspicuous. Similarly, a large and rapid change was seen in the magnetic field only for plasmoids observed at the magnetopause. The high-energy electron spectrum (Fig. 5f) is magnetosheath-like inside the plasmoids, which indicates that these were not on the closed field lines of the magnetosphere. The ion spectrum (Fig. $5 \mathrm{~g}$ ), on the other hand, shows that high-energy ions, from $10 \mathrm{keV}$ and upward, were present occasionally during the period when plasmoids appeared. This is seen in Fig. $5 \mathrm{~g}$ when the observed flux above $10 \mathrm{keV}$ is similar to that of the magnetosphere, for example at 09:04, 09:37 and 10:19, but also at many other times, and about two orders of magnitude higher than that of the magnetosheath after 10:30.

The first and the next to last plasmoids that are shown in Fig. 5 (marked by downward pointing black triangles above Fig. 5c) are enlarged in Figs. 6 and 7.

The plasmoid that was observed at the magnetopause at 08:00:39 on 15 March 2007 by Cluster 1 is shown in Fig. 6. The plasmoid speed was larger than the average magnetosheath speed by more than a factor of two. The velocity was directed mostly in the negative $x$ direction. The velocity direction is illustrated by the red arrows in Fig. 8 which shows position of the Cluster 1 spacecraft (marked by black circles) at 08:00 and 10:21 on 15 March 2007. The positions of the three other spacecraft at 08:00 are marked with plus signs. The left-hand panel shows the $x-z$ plane and the right-hand panel shows the $y-z$ plane. A Shue model magnetopause (Shue et al., 1997) is shown by the dashed line in the left-hand panel. The solar wind parameters used as input to the Shue model were mean values of measurements by the Wind spacecraft over the period from 08:00 to 08:10 in Fig. 5. The magnetic field direction on the inside of the magnetopause is shown by the blue arrows. The velocity that is shown by the arrow in Fig. 8 is the velocity at the time of the negative $v_{x}$ peak in Fig. $6 \mathrm{~b}$. The magnetic field direction is an average of $\boldsymbol{B}$ observed by FGM between 60 and $30 \mathrm{~s}$ before the arrival of the plasmoid, and it thus represents the direction of the magnetic field inside the magnetosphere. 


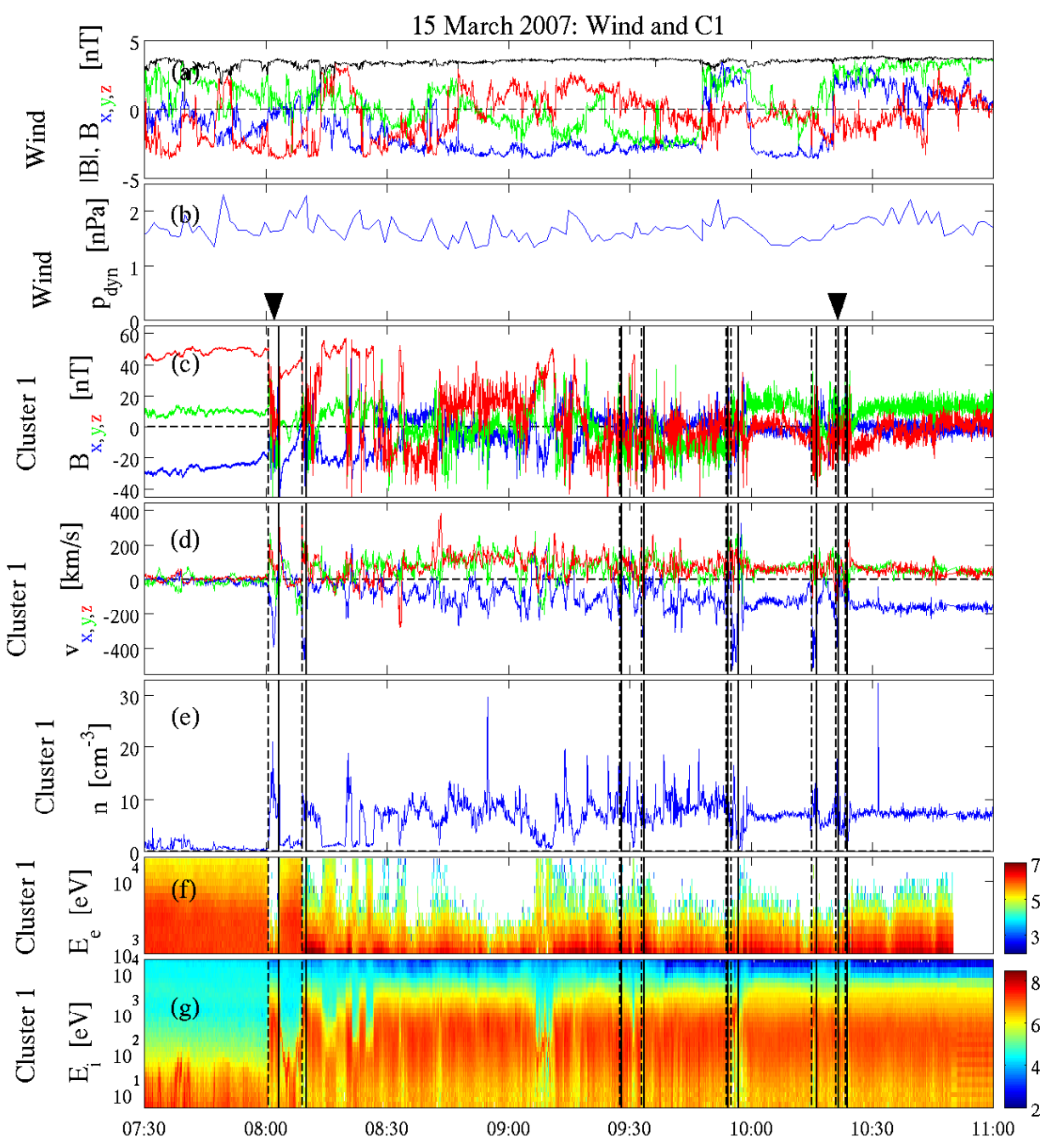

Figure 5. Data obtained by the Wind and Cluster 1 spacecraft on 15 March 2007. (a) Solar wind magnetic field $B_{x}$ (blue), $B_{y}$ (green), $B_{z}$ (red), and $|\boldsymbol{B}|$ (black); and (b) solar wind dynamic pressure, both measured by the Wind spacecraft. Panels (c-g) show data from Cluster 1. (c) Magnetic field $B_{x}$ (blue), $B_{y}$ (green), and $B_{z}$ (red); (d) ion velocity $v_{x}$ (blue), $v_{y}$ (green), and $v_{z}$ (red); (e) ion density; (f) electron energy spectrum above $1 \mathrm{keV}$, with the colour coded scale showing the logarithm of the omnidirectional differential particle flux in units of $\mathrm{cm}^{-2} \mathrm{~s}^{-1} \mathrm{sr}^{-1} \mathrm{keV}^{-1}$; and (g) the ion energy spectrum, where the colour scale shows the logarithm of the omnidirectional differential particle flux, in units of $\mathrm{cm}^{-2} \mathrm{~s}^{-1} \mathrm{sr}^{-1} \mathrm{keV}^{-1}$. The components of the vector quantities in panels (a), (c), and (d) are shown in GSE coordinates. The vertical lines mark the plasmoids that have been identified in Table 1. The first and the next to last plasmoids (marked by downward pointing black triangles above panel c) are discussed in the text, and they are shown on a larger scale in Figs. 6 and 7.

The magnetic field in the plasmoid is weaker than that of the magnetosphere and its direction is variable as is seen in Fig. 6a. At the time of the most negative $v_{x}$ there was a large component of the plasmoid velocity perpendicular to the magnetic field in the magnetosphere, and, assuming that the field is at least approximately in the plane of the magnetopause, the velocity was also largely perpendicular to the magnetopause. This is confirmed by an analysis of the magnetopause crossing times, determined from the magnetic field data of the four spacecraft $(\mathrm{C} 1$ crossed the magnetopause at 08:00:53.3; $\mathrm{C} 2$ at 08:00:41.6; $\mathrm{C} 3$ at 08:00:28.4; and C4 at 08:00:35.6), which gives a magnetopause moving in the direction of its normal at a velocity $\boldsymbol{v}=(-107 ; 11.4 ;-15.3) \mathrm{km} \mathrm{s}^{-1}$. The magnetopause normal is dominated by its $x$ component.

Towards the end of the plasmoid observation $v_{x}$ changes sign and becomes positive. This indicates that the plasmoid made an indentation on the magnetopause and then bounced back, in the same way as in the observation by Shue et al. (2009). This type of magnetopause motion can be compared to that which is caused by a surface wave as was observed by Plaschke et al. (2013a). With three of the THEMIS spacecraft, one at the magnetopause and one on either side of it, those authors were able to measure the velocity field of a 


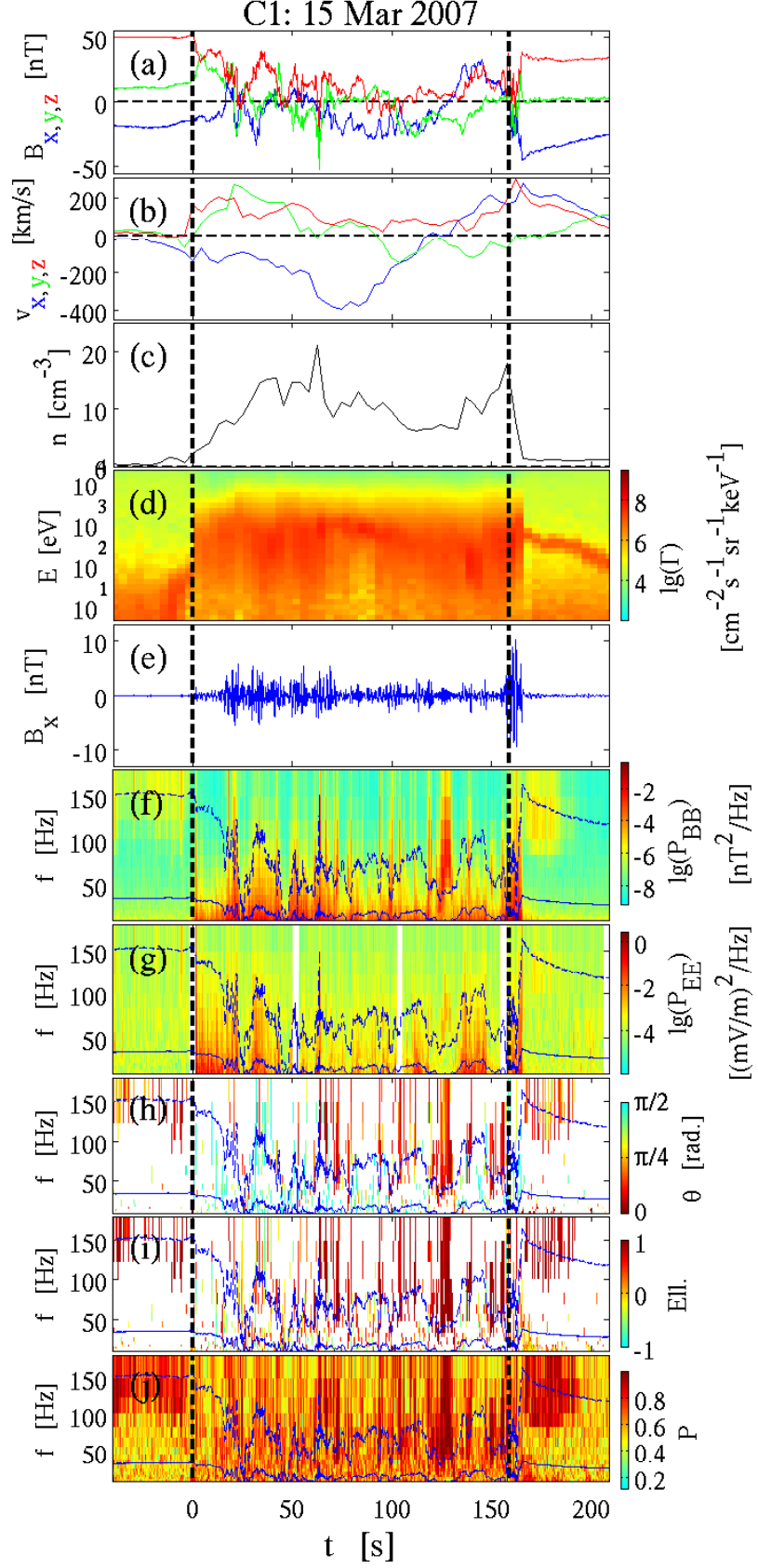

Figure 6. Data obtained by Cluster 1 on 15 March 2007. On the horizontal axis, time $t=0$ corresponds to 08:00:39 UT. (a) Magnetic flux density in GSE coordinates; (b) ion bulk velocity in GSE coordinates; (c) ion density; (d) omnidirectional ion energy spectrum; (e) the $x$ component of $\boldsymbol{B}$ measured by STAFF in the $0.6 \mathrm{~Hz} \leq f \leq 180 \mathrm{~Hz}$ frequency range; (f) power spectral density of $|\boldsymbol{B}|$; (g) power spectral density of $|\boldsymbol{E}|$; (h) propagation angle, i.e. the angle between $\boldsymbol{k}$ and $\boldsymbol{B}$; (i) ellipticity; (j) degree of polarisation. The vertical dashed lines mark the beginning and end of the plasmoid identified in Table 1 . The blue curves on panels $(\mathbf{f}-\mathbf{j})$ show $0.1 f_{\text {ce }}$ (upper curve) and $f_{\text {lh }}$ (lower curve).

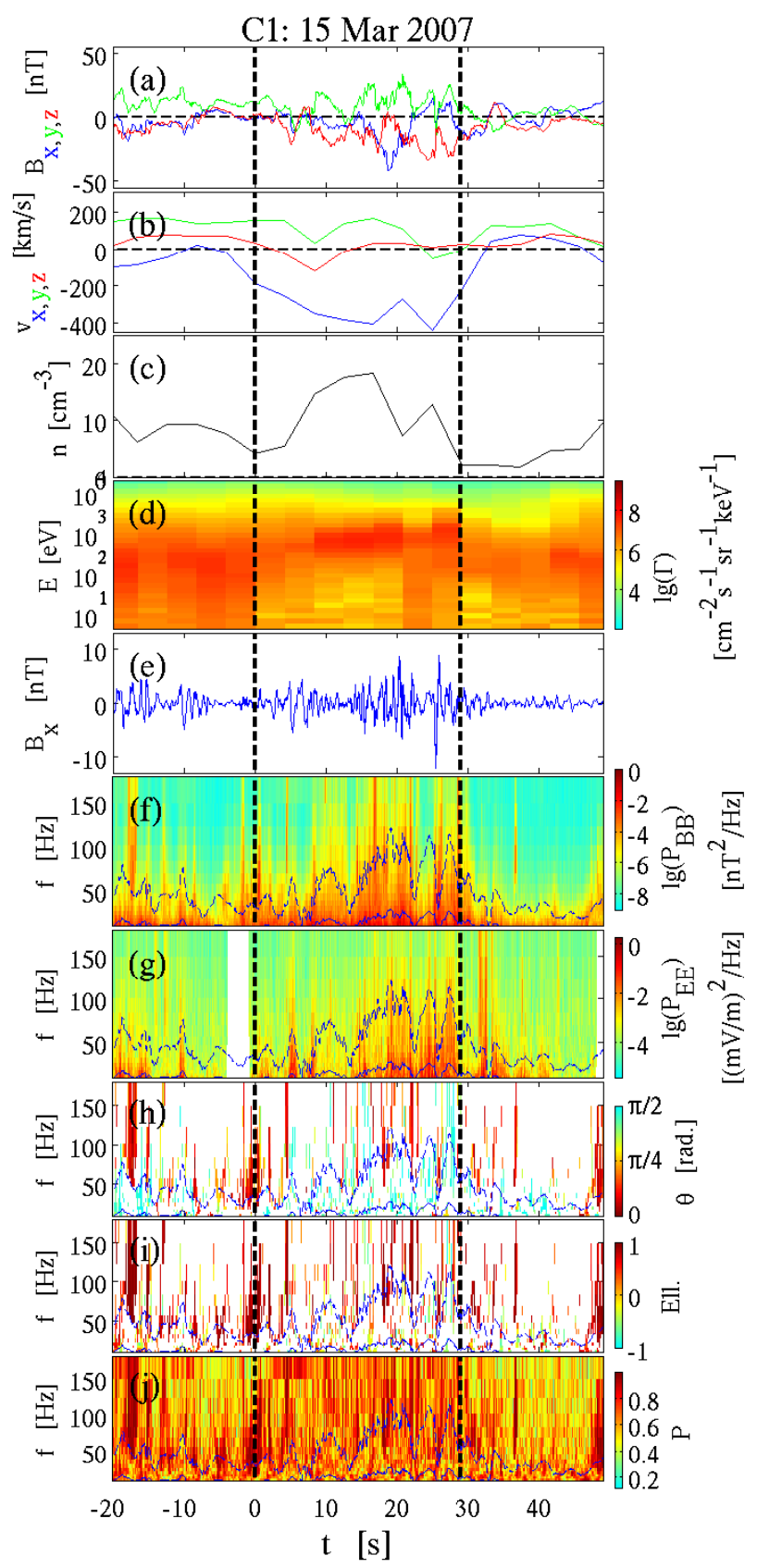

Figure 7. Data obtained by Cluster 1 on 15 March 2007. On the horizontal axis, time $t=0$ corresponds to 10:21:05 UT. (a) Magnetic flux density in GSE coordinates; (b) ion bulk velocity in GSE coordinates; (c) ion density; (d) omnidirectional ion energy spectrum; (e) the $x$ component of $\boldsymbol{B}$ measured by STAFF in the $0.6 \mathrm{~Hz} \leq f \leq 180 \mathrm{~Hz}$ frequency range; (f) power spectral density of $|\boldsymbol{B}|$; (g) power spectral density of $|\boldsymbol{E}|$; (h) propagation angle, i.e. the angle between $\boldsymbol{k}$ and $\boldsymbol{B}$; (i) ellipticity; (j) degree of polarisation. The vertical dashed lines mark the beginning and end of the plasmoid identified in Table 1 . The blue curves on panels $(\mathbf{f}-\mathbf{j})$ show $0.1 f_{\text {ce }}$ (upper curve) and $f_{\text {lh }}$ (lower curve). 


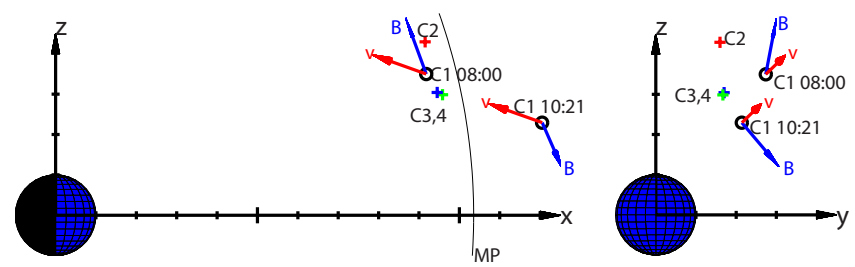

Figure 8. Position of the Cluster spacecraft relative to the planet on 15 March 2007. The Cluster 1 positions are marked "o" for the times 08:00 and 10:21, and the positions of the other three spacecraft at 08:00 are marked "+": red for C2, green for C3, and blue for C4. The blue arrows show the direction of the magnetic field and the red arrows show the plasmoid velocity direction for the plasmoids encountered by $\mathrm{C} 1$ at 08:00 and 10:21. The magnetic field direction shown is the mean value in the period from 60 to $30 \mathrm{~s}$ before the plasmoid arrived at the spacecraft. The left-hand panel shows the $x-z$ plane in GSE coordinates and the right-hand panel shows the $y-z$ plane. The dashed black curve in the left panel shows a Shue model magnetopause.

magnetopause surface wave that passed by the spacecraft. Also there both magnetosheath plasma and magnetospheric plasma were observed, but the magnetosheath plasma moved tangentially along the magnetopause, and the plasma on the magnetospheric side moved back and forth along the magnetopause normal. In our case, the dense magnetosheath plasma moves along the normal, driving the magnetopause motion at the point in space where it was detected by the spacecraft.

On the right-hand side of Fig. $6 \mathrm{~d}$ an ion population which is narrow in energy can be seen outside the plasmoid just after the spacecraft re-entered the magnetosphere. This is a cold ion population of ionospheric origin. Figure 9 shows the electric field measured by the EFW (Electric Field and Waves) instrument (Gustafsson et al., 2001) during the period when these cold ions were observed. The electric field was oriented in the $y$ direction and peaked at $E_{y}=19 \mathrm{mV} \mathrm{m}^{-1}$, which combined with the magnetic field at the time, shown in Fig. 6a, yields an $\boldsymbol{E} \times \boldsymbol{B} / \boldsymbol{B}^{2}$ drift velocity with both the $x$ and $z$ components near $200 \mathrm{~km} \mathrm{~s}^{-1}$. This is consistent with the measured ion velocity shown in Fig. 6b. Thus, the magnetospheric plasma inside the magnetopause is set in motion by the plasmoid impact, and individual particles in the near magnetopause magnetosphere experience this as an $\boldsymbol{E} \times \boldsymbol{B}$ drift. In Fig. 5g, which shows the ion spectrum on a longer timescale, the cold plasma can be seen to slow down and then speed up again just before the arrival of the next plasmoid at 08:09:01.

In Fig. 7 a plasmoid that was detected by Cluster 1 at 10:21:05 UT on 15 March 2007 is shown. It is seen in Fig. 7a and $d$ that the magnetic field and ion energy spectrum both before and after the plasmoid were typical of the magnetosheath. Thus this plasmoid was in the magnetosheath, and not interacting with the magnetopause at the time of observation. The peak negative $v_{x}$ value was close to that of the other plasmoid in Fig. 6. The direction of the velocity, at the

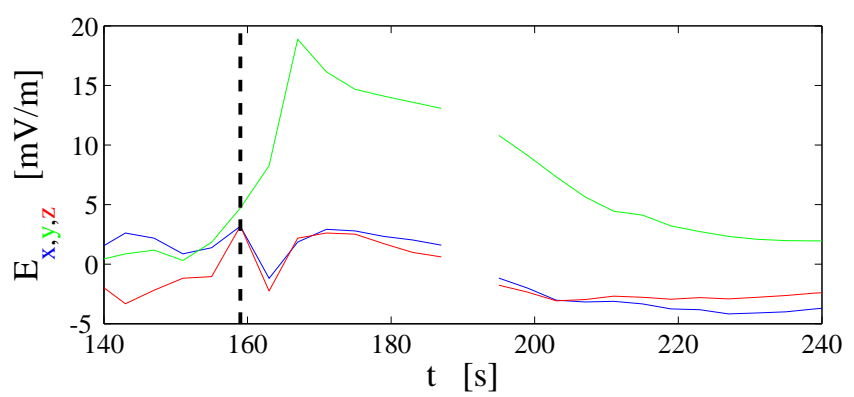

Figure 9. Electric field measured by the EFW instrument on the Cluster 1 spacecraft after the first plasmoid observation on 15 March. The timescale is the same as that in Fig. 6. The dashed line at $t=159 \mathrm{~s}$ marks the end of the plasmoid.

time of the peak negative $v_{x}$, is illustrated in Fig. 8, and it is in the same direction as for the other plasmoid. The magnetic field direction that is shown in Fig. 8 is again an average of $\boldsymbol{B}$ observed by FGM between 60 and $30 \mathrm{~s}$ before the arrival of the plasmoid, and in this case this means that it is a magnetosheath field that is shown. The density in the plasmoid is somewhat higher than that of the surrounding magnetosheath, and the magnetic field exhibits fluctuations.

Figures 6e and 7e show the oscillating $x$ component of the magnetic field $B_{x}$ in the $0.6 \mathrm{~Hz} \leq f \leq 180 \mathrm{~Hz}$ frequency range that was measured by the STAFF (Spatio Temporal Analysis of Field Fluctuations) instrument (CornilleauWehrlin et al., 1997). Panels (f-j) of Figs. 6 and 7 show wave propagation parameters in the $10 \mathrm{~Hz} \leq f \leq 180 \mathrm{~Hz}$ frequency range that were calculated from the STAFF data using the singular value decomposition method as described by Santolík et al. (2003). Spectral powers of $\boldsymbol{E}$ and $\boldsymbol{B}$ were obtained using Morlet wavelet analysis. In these two figures, panels (f) show the power spectral density of the magnetic field, $P_{\mathrm{BB}}$, with all three components added together. Panel $(\mathrm{g})$ shows the sum of the power spectral density, $P_{\mathrm{EE}}$, for the two measured electric field components. Panel (h) shows the propagation angle $\theta=\pi / 2-$ $|\pi / 2-\arccos (\boldsymbol{k} \cdot \boldsymbol{B} /(|k||B|))|$, which means that $\theta=0$ corresponds to $\boldsymbol{k}$ being parallel or anti-parallel to $\boldsymbol{B}$ and $\theta=$ $\pi / 2$ to it being perpendicular. Panels (i) show the ellipticity, which is defined as the ratio of the minor to the major axes of the ellipse described by the component of the wave magnetic field, perpendicular to the wave vector. For waves that are right-hand polarised with respect to $\boldsymbol{B}$ the ellipticity is positive. The (j) panels show the degree of polarisation, which represents the ratio between the polarised part of the wave intensity and the total wave intensity. The degree of polarisation is one for purely polarised waves and zero for completely unpolarised waves. The blue curves on panels $(f-j)$ show one tenth of the electron cyclotron frequency, $0.1 f_{\text {ce }}$, (upper curve) and the lower hybrid frequency $f_{\mathrm{lh}}=f_{\mathrm{pi}} / \sqrt{1+f_{\mathrm{pe}}^{2} / f_{\mathrm{ce}}^{2}}$ (lower curve), where $f_{\mathrm{pi}}$ is the ion 
plasma frequency and $f_{\mathrm{pe}}$ the electron plasma frequency. The electron cyclotron frequency is computed from FGM data and the plasma frequencies from CIS-HIA data. The quantities in panels (h) and (i) are shown only for times and frequencies where the degree of polarisation is 0.6 or greater, since these quantities become unreliable for lower degrees of polarisation.

A magnetic field signal was measured inside the plasmoid that arrived at 08:00:39 UT as is seen in Fig. 6e. The component $B_{x}$ is the one component that is shown. However, the other two components both show a similar pattern. In the case of Fig. 6, the spacecraft was inside the magnetosphere both before and after the encounter with the plasmoid, and there the amplitude was much lower. This is seen also in the power spectral density of the magnetic field, which is shown in Fig. $6 f$ and in that of the electric field in Fig. 6g. Two different signatures can be distinguished in the power spectral density diagram. First, there are fluctuations around the lower hybrid frequency that can be seen in both the electric and magnetic fields. These are present throughout the duration of the plasmoid. Where the degree of polarisation is high enough that anything can be said about it, $\theta \approx \pi / 2$ in this frequency range, as seen in the lower part of Fig. $6 \mathrm{~h}$, meaning that these are waves propagating mostly perpendicular to $\boldsymbol{B}$. Secondly, there are short bursts of wave energy around and above $0.1 f_{\mathrm{ce}}$. While present in both the electric and magnetic fields, they are more easily distinguished in the magnetic power spectral density in Fig. 6f. Examining panels (hj) for these bursts we see that they have a high degree of polarisation, an ellipticity close to 1 , and a low propagation angle. These bursts can therefore be identified as whistler mode waves. In the near-magnetopause magnetosphere - that is to say, just before and just after the plasmoid observation - such whistler mode waves are seen at $0.1 f_{\text {ce }}$ during a longer period, but with a lower amplitude, than that of the burst inside the plasmoid.

Also for the plasmoid that was encountered at 10:21:05 UT the oscillatory electric and magnetic energies were larger inside than in the surrounding plasma. This is seen in panels (e-g) of Fig. 7. The difference between the power spectral densities inside the plasmoid and those in its immediate surroundings are not as prominent as those of the other plasmoid, which was shown in Fig. 6, because the plasmoid of Fig. 7 was surrounded by magnetosheath plasma, which has a higher background fluctuation level. Examining Fig. 7f-j, it is seen that also in this plasmoid there are bursts of whistler mode waves at and above $0.1 f_{\text {ce }}$, and low-frequency waves of mostly perpendicular propagation appear from around $f_{\mathrm{lh}}$ up to about $0.1 f_{\text {ce }}$.

\section{Wave amplitude statistics}

The wave amplitudes observed inside the two plasmoids examined in Sect. 4 were higher than in the plasma observed by the spacecraft just before and just after the plasmoid encounter. To answer the question of whether or not a high wave amplitude is a typical property of plasmoids we present statistics of all plasmoids that were observed during March 2007.

An analysis of the wave propagation parameters similar to that conducted for the two plasmoids in Sect. 4 shows that waves in the lower hybrid frequency range are present in all plasmoids in Table 1. Whistler mode waves are present at detectable levels in all plasmoids except those that were observed on 24 March 2007, when the magnetic field in the magnetosheath was more than $60 \mathrm{nT}$. That this is significantly higher than on the other days can be seen in Table 2. We have used data from the STAFF instrument to integrate the power spectral densities of the magnetic and electric fields for each plasmoid in the frequency range $10 \mathrm{~Hz} \leq f \leq$ $500 \mathrm{~Hz}$. We add together the contributions from the three components of $\boldsymbol{B}$ and the two measured components of $\boldsymbol{E}$ to form $P_{\mathrm{BB}}$ and $P_{\mathrm{EE}}$ respectively. Then the average is formed for each plasmoid, and the result is converted to energy units in order to obtain the average magnetic, $\left\langle P_{\mathrm{BB}} / \mu_{0}\right\rangle$, and electric, $\left\langle\epsilon_{0} P_{\mathrm{EE}}\right\rangle$, energy densities for each plasmoids. These values are included in Table 1.

As a reference, the wave energy densities measured in the magnetosheath are shown in Table 3. These energy densities for the magnetosheath are calculated in the same way as those of the plasmoid, and the averages are formed over the first $10 \mathrm{~min}$ the spacecraft spent in the unperturbed magnetosheath, as represented by the vertical thick solid black line in Fig. 2. This means that the plasmoids are not included in the magnetosheath average, and also that we avoid including magnetospheric data that otherwise could interfere when there are multiple magnetopause crossings.

The wave energy density data in Tables 1 and 3 are illustrated in Fig. 10. Panel (a) shows the magnetic energy density of each plasmoid normalised to the mean magnetic energy density in the magnetosheath (as in Table 3) of the orbit on which it was observed. For reference the mean magnetosheath energy density is shown in panel (b). Panel (c) shows the electric energy density for each plasmoid normalised to the corresponding magnetosheath value, which is shown in panel (d). The mean energy densities in panels (b) and (d) were calculated during the first $10 \mathrm{~min}$ each spacecraft spent in the undisturbed magnetosheath. To estimate how much the fluctuation level in the magnetosheath varies we divided the same $10 \mathrm{~min}$ into 20 shorter intervals of $30 \mathrm{~s}$ each. We determined the energy density for each of these intervals and computed the standard deviation of the logarithm of these values. The corresponding energy density is shown by the error bars in panels (b) and (d). The 30 s interval length was chosen as it is approximately as long as the duration of a plasmoid and thus represents a relevant timescale. The horizontal red dashed lines in panels (a) and (c) show where the normalised energy density is equal to one. Except in a few 
Table 3. Magnetosheath mean energy density of the magnetic $\left\langle P_{\mathrm{BB}} / \mu_{0}\right\rangle$ and electric $\left\langle\epsilon_{0} P_{\mathrm{EE}}\right\rangle$ fluctuations in the frequency range $10 \mathrm{~Hz} \leq$ $f \leq 500 \mathrm{~Hz}$. The values are computed from data taken during the first $10 \mathrm{~min}$ spent in the magnetosheath after the last plasmoid was seen by Cluster 1 and 3, respectively, on each date shown.

\begin{tabular}{cccccc}
\hline \multirow{2}{*}{ Date } & \multicolumn{2}{c}{$\left\langle P_{\mathrm{BB}, \mathrm{MS}} / \mu_{0}\right\rangle$} & & \multicolumn{2}{c}{$\left\langle\epsilon_{0} P_{\mathrm{EE}, \mathrm{MS}}\right\rangle$} \\
\cline { 2 - 3 } \cline { 5 - 6 } & $\mathrm{C} 1$ & $\mathrm{C} 3$ & & $\mathrm{C} 1$ & $\mathrm{C} 3$ \\
& $\left(\mathrm{~J} \mathrm{~m}^{-3}\right)$ & $\left(\mathrm{J} \mathrm{m}^{-3}\right)$ & & $\left(\mathrm{J} \mathrm{m}^{-3}\right)$ & $\left(\mathrm{J} \mathrm{m}^{-3}\right)$ \\
\hline $2007-03-01$ & $5.9 \times 10^{-15}$ & $3.0 \times 10^{-15}$ & & $1.2 \times 10^{-19}$ & $6.1 \times 10^{-20}$ \\
$2007-03-03$ & $4.5 \times 10^{-16}$ & $4.6 \times 10^{-16}$ & & $5.3 \times 10^{-20}$ & $2.4 \times 10^{-20}$ \\
$2007-03-05$ & $3.0 \times 10^{-14}$ & $2.9 \times 10^{-14}$ & & $3.8 \times 10^{-18}$ & $2.6 \times 10^{-18}$ \\
$2007-03-08$ & $4.8 \times 10^{-15}$ & $3.0 \times 10^{-15}$ & & $2.5 \times 10^{-20}$ & $1.7 \times 10^{-20}$ \\
$2007-03-10$ & $2.1 \times 10^{-15}$ & $1.3 \times 10^{-15}$ & & $1.2 \times 10^{-19}$ & $5.7 \times 10^{-20}$ \\
$2007-03-12$ & $2.3 \times 10^{-15}$ & $1.7 \times 10^{-15}$ & & $8.2 \times 10^{-19}$ & $5.0 \times 10^{-19}$ \\
$2007-03-15$ & $1.0 \times 10^{-13}$ & $6.9 \times 10^{-14}$ & & $3.3 \times 10^{-18}$ & $2.7 \times 10^{-18}$ \\
$2007-03-17$ & $2.7 \times 10^{-15}$ & $2.4 \times 10^{-15}$ & & $5.2 \times 10^{-20}$ & $1.8 \times 10^{-20}$ \\
$2007-03-20$ & $1.3 \times 10^{-15}$ & $7.0 \times 10^{-16}$ & & $2.6 \times 10^{-20}$ & $2.2 \times 10^{-20}$ \\
$2007-03-22$ & $3.3 \times 10^{-15}$ & $2.6 \times 10^{-15}$ & & $3.7 \times 10^{-20}$ & $5.4 \times 10^{-20}$ \\
$2007-03-24$ & $4.2 \times 10^{-16}$ & $2.0 \times 10^{-17}$ & & $2.9 \times 10^{-19}$ & $2.9 \times 10^{-20}$ \\
$2007-03-27$ & $3.9 \times 10^{-15}$ & $2.6 \times 10^{-15}$ & & $1.2 \times 10^{-19}$ & $9.0 \times 10^{-20}$ \\
$2007-03-29$ & $7.5 \times 10^{-16}$ & $7.9 \times 10^{-16}$ & & $1.1 \times 10^{-19}$ & $4.2 \times 10^{-20}$ \\
\hline
\end{tabular}

cases, the wave energies measured inside the plasmoids are larger than the reference magnetosheath values.

\section{Low-frequency waves and cold ions in the magnetosphere}

Figure 11 shows data obtained by Cluster 1 between 04:15 and 08:00 UT on 15 March 2007. At the beginning of the period shown the spacecraft was located deep inside the magnetosphere, as can be seen in Fig. 1. The period shown in Fig. 11 ends at 08:00, when the spacecraft first reached the magnetopause, as discussed in Sect. 4. Figure 11b shows the magnetic field that has been high-pass filtered with a $-3 \mathrm{~dB}$ cutoff at $1.4 \mathrm{mHz}$. A wave at $3-4 \mathrm{mHz}$ is seen throughout the panel. This is in the Pc5 frequency range, which spans from $2 \mathrm{mHz}$ to $7 \mathrm{mHz}$. The wave amplitude was low at the start of the period shown; then it fluctuated, showing higher values for some time around 05:00, and from 05:55 it remained at about $5 \mathrm{nT}$ until the magnetopause was encountered at 08:00. The EFW instrument measures two components of the electric field in the spin plane of the satellite. Three electric field components in the GSE coordinate system are then computed under the assumption that $\boldsymbol{E} \cdot \boldsymbol{B}=0$. These three components are shown in Fig. 11c. Also here the wave is seen during the same interval as in Fig. 11b. The electric field amplitude was about $5 \mathrm{mV} \mathrm{m}^{-1}$ during most of the observation.

In the ion energy spectrum, which is shown in Fig. 11a as the omnidirectional energy flux, patches of cold ions are seen during the same period of time as when the wave was observed in the electric and magnetic fields. The temperature of the cold ion population is approximately $5 \mathrm{eV}$. Data from the mass sensitive CODIF detector show that these ions are protons. There is no significant flux of $\mathrm{He}^{+}$or $\mathrm{O}^{+}$ions. The density of the cold population was determined by the Whisper instrument (Décréau et al., 1997; Décréau et al., 2001), and it is shown by the red curve in Fig. 11d. It decreases slowly from 4 to $2 \mathrm{~cm}^{-3}$ showing that a cold ion population was present throughout the interval under consideration, from geocentric distances of about $5 R_{\mathrm{E}}$ to $10 R_{\mathrm{E}}$. The blue curve in the same panel shows the density measured by CISHIA. The latter instrument can only detect the cold ions when their energy is above threshold. This caused the apparent oscillations in the blue curve, whereas the true density was not oscillating. The detection threshold of the CIS-HIA instrument itself is $5 \mathrm{eV}$. In addition to that, the ions must overcome the spacecraft potential, which was between 3 and $9 \mathrm{~V}$ during the period shown in Fig. 11.

The $z$ component of the $\boldsymbol{E} \times \boldsymbol{B} / B^{2}$ velocity measured by the EFW and FGM instruments is shown in Fig. 11e (black curve) together with the $z$ component of the ion velocity measured by CIS-HIA (red curve). The agreement between the two curves is good when the cold ion flux (Fig. 11a) is high. $\boldsymbol{E} \times \boldsymbol{B}$ drifting ions of different masses move with the same drift velocity, and they would therefore be seen at different energies by the CIS-HIA detector. Only a single cold ion population can be seen in Fig. 11a, confirming the CODIF observation that there are no significant populations of ions other than protons.

We can estimate the Alfvén speed, $v_{A}=B / \sqrt{\mu_{0} n m_{\mathrm{p}}}$, using a density of $n=2 \times 10^{5} \mathrm{~m}^{-3}$, and a dc magnetic field of $B=60 \mathrm{nT}$, which is the value that was observed at 07:00, and we obtain $v_{A}=9.3 \times 10^{5} \mathrm{~m} \mathrm{~s}^{-1}$. This is close to the observed ratio of the electric and magnetic field amplitudes of 


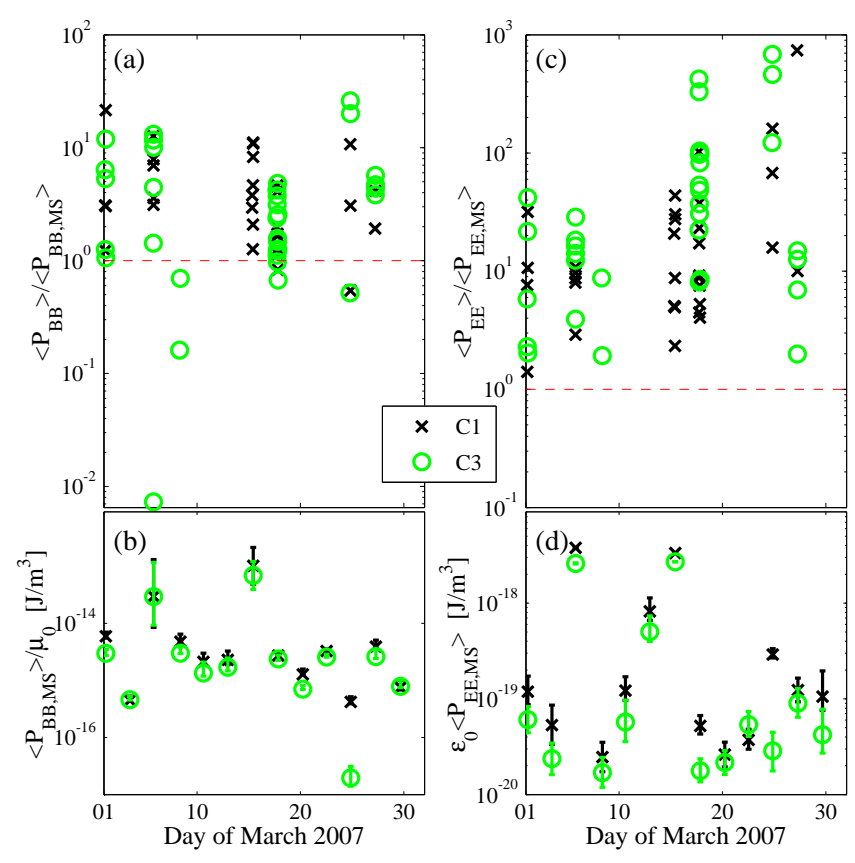

Figure 10. Magnetic and electric energy of waves measured by STAFF. (a) Magnetic energy density for each plasmoid measured by Cluster 1 and 3 normalised to the magnetosheath value of the same date; (b) magnetic energy density in the magnetosheath; (c) electric energy density for each plasmoid normalised to the magnetosheath value of the same date; and (d) electric energy density in the magnetosheath. The magnetosheath values in panels (b) and (d) are shown for all outbound orbits, also those when no plasmoids were observed. The error bars indicate the values corresponding to one standard deviation upward and downward of the logarithm of the energy density computed in $30 \mathrm{~s}$ intervals. In all panels, observations made by Cluster 1 are marked " $x$ " and observations made by Cluster 3 are marked "o", the former black and the latter green.

the wave $\Delta E / \Delta B \approx\left(5 \mathrm{mV} \mathrm{m}^{-1}\right) /(5 \mathrm{nT})=10^{6} \mathrm{~m} \mathrm{~s}^{-1}$. We therefore assume these waves to be Alfvénic. The electron temperature, measured by the PEACE instrument, was approximately $2 \times 10^{6} \mathrm{~K}$. This leads to a sound speed $c_{\mathrm{s}} \approx$ $\sqrt{k_{\mathrm{B}} T_{\mathrm{e}} / m_{\mathrm{p}}}=1.3 \times 10^{5} \mathrm{~m} \mathrm{~s}^{-1}$. With an Alfvén speed seven times higher than the sound speed, the phase speeds of the Alfvén wave and the fast and slow modes differ by no more than $1 \%$, and we cannot distinguish between them.

The cold plasma that was seen after the impact of a plasmoid at the magnetopause in Fig. 6d is quite similar to that which is seen in connection with the wave in Fig. 11. They are both cold populations that undergo $\boldsymbol{E} \times \boldsymbol{B}$ drifts. After the impact of the plasmoid in Fig. 6, the electric field in the magnetosphere shown in Fig. 9 led to drift velocity components near $200 \mathrm{~km} \mathrm{~s}^{-1}$ in both the $x$ and $z$ directions. This drift speed that was observed close to the magnetopause was a few times higher than the drift speed that was observed deeper inside the magnetosphere. The picture that emerges is that of plasmoids impacting on the magnetopause that set the cold ions in motion through the means of the $\boldsymbol{E} \times \boldsymbol{B}$ drift.
This motion becomes the source of the Alfvénic waves that are seen all along the spacecraft trajectory.

\section{Conclusions and discussion}

Observations of high-speed plasmoids or jets have been reported in recent years by several authors. We have examined data from two of the Cluster spacecraft obtained during the month of March 2007. In this period the spacecraft traversed the dayside magnetosheath 13 times, and we detected plasmoids on seven of these orbits. Plasmoids are seen both at the magnetopause and away from it in the magnetosheath. The extent of the plasmoids in the direction of the plasma flow was estimated from their duration and the peak value of the measured ion velocity within the plasmoid. It was in a range from $0.5 R_{\mathrm{E}}$ to $20 R_{\mathrm{E}}$ with a median value of $4.9 R_{\mathrm{E}}$. Estimating the magnetosheath thickness to about $5 R_{\mathrm{E}}$, we can conclude that at least half of the plasmoids are smaller than that value. The estimate of $4.9 R_{\mathrm{E}}$ is an overestimate as we have not integrated the velocity but instead used $T \cdot \max (|v|)$ as the extent parallel to the flow. The direction from Cluster 1 to 3 was approximately perpendicular to the direction of the plasma flow. A diameter of about $7.2 R_{\mathrm{E}}$ based on three quarters of the plasmoids observed by spacecraft 1 also being observed on spacecraft 3 can be seen as an upper limit to the spatial extent in this direction. For this purpose the two spacecraft were considered to be observing the same plasmoid if there was an overlap in time between the two observations. In the event that some of these were really two separate plasmoids appearing at the two spacecraft, the size estimate should be adjusted downward. The majority of the plasmoids were smaller than the magnetopause diameter, which was approximately $10 R_{\mathrm{E}}$ in the region of these observations. Our estimate is within the range reported by Karlsson et al. (2012), and it is larger than the estimates by other authors (Němeček et al., 1998; Archer et al., 2012; Plaschke et al., 2013b). This is expected, since we intentionally overestimated the size in order to confirm that it is reasonable to describe the observed structures as plasmoids.

We have used the $x$ component of the velocity to define the plasmoids, whereas Karlsson et al. (2012) used the density, and others have used the dynamic pressure, which is a combination of both velocity and density. As processes that lead to increased density may be different from those that increase velocity, there is a possibility that studies that use different definitions favour the selections of plasmoids that are created in different ways. However, plasmoids showing enhancements of both density and velocity meet the selection criteria of all the studies, creating an overlap between the populations under consideration.

Integrating the power spectral densities of the magnetic and electric fields in the 10 to $500 \mathrm{~Hz}$ frequency range shows that the energy density of waves is higher inside the plasmoids than in the surrounding magnetosheath. For the 


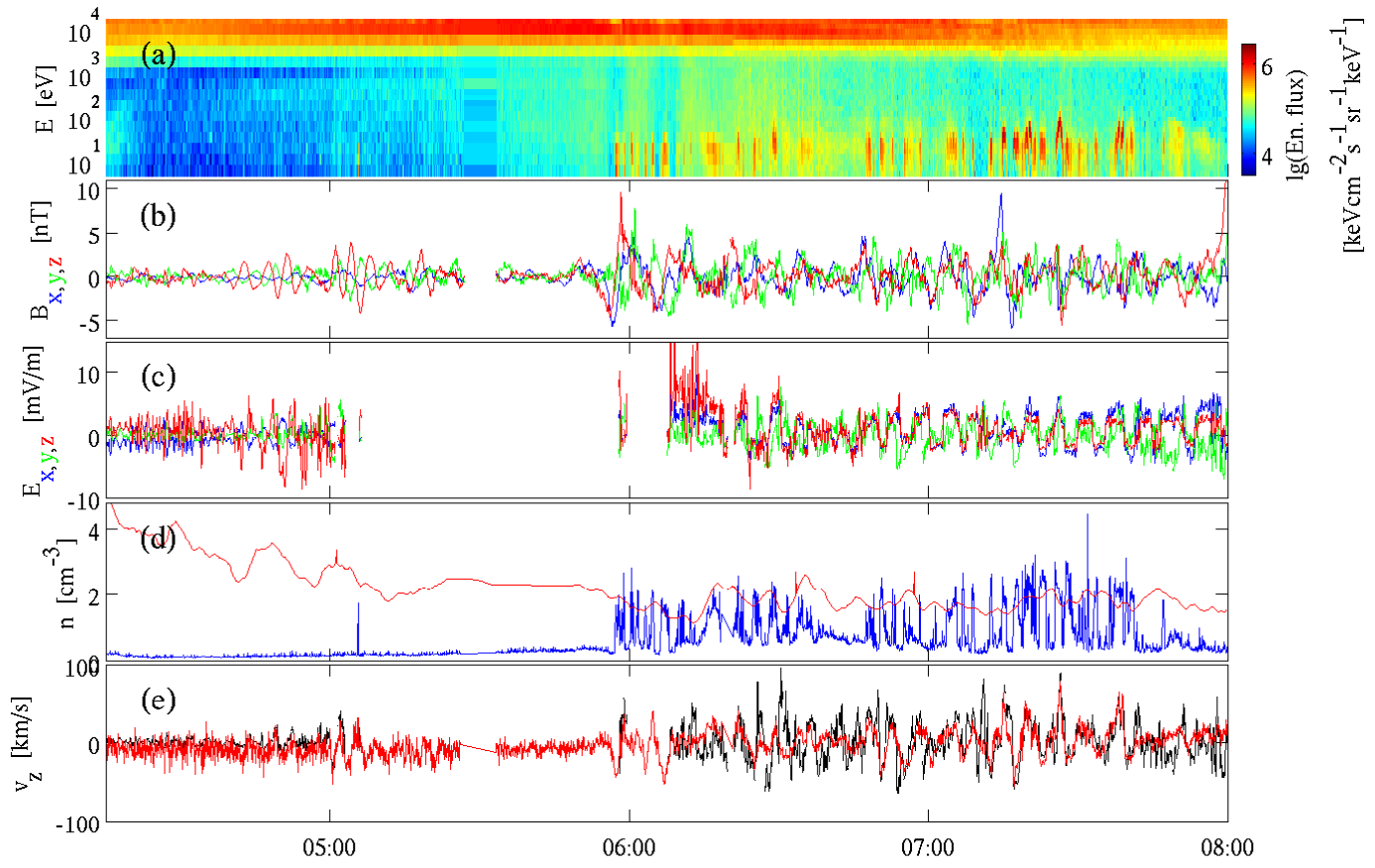

Figure 11. Data from Cluster 1 between 04:15 and 08:00 on 15 March 2007. (a) Omnidirectional ion energy flux. (b) Magnetic field in the frequency range $1.4 \mathrm{mHz} \leq f \leq 0.25 \mathrm{~Hz}$. (c) Electric field for $f \leq 0.25 \mathrm{~Hz}$. (d) Density measured by CIS-HIA (blue curve) and Whisper (red curve). (e) The GSE $z$ component of the ion velocity measured by CIS-HIA (red curve) and the $z$ component of $\boldsymbol{E} \times \boldsymbol{B} /|\boldsymbol{B}|^{2}$ computed from EFW and FGM data (black curve).

electric field spectrum the energy density is higher by a factor of nearly 1000 in some cases, which is seen in Fig. 10c. The waves fall into two distinct categories, namely waves in the lower hybrid frequency range and whistler mode waves that appear at or above one tenth of the electron cyclotron frequency. Waves of both kinds appear both inside the plasmoids and in the rest of the magnetosheath, but their amplitudes are higher inside the plasmoids.

No effort has been made to model how the observed waves are generated. However, we note that as the speed of the plasmoids is higher than that of the surrounding plasma, the plasma populations are in relative motion, and there is kinetic energy available for conversion into wave energy. In laboratory experiments, currents have been seen to develop near the plasmoid boundaries, and these currents drive lower hybrid waves through a modified two-stream instability (Hurtig et al., 2005). Simulations in the small plasmoid regime (perpendicular width below the ion gyro radius) show that such waves are present throughout the plasmoid (Gunell et al., 2008). For larger plasmoids one would expect waves to propagate from the surface toward the plasmoid interior.

Whistler mode waves have been seen in the magnetosphere near the magnetopause in tube-like structures with small $(\approx 150 \mathrm{~km})$ perpendicular dimensions (Stenberg et al., 2007). The whistler mode waves we observe inside the plasmoids appear in short bursts, indicating that they are confined to narrow structure also in this case. In the laboratory, large-amplitude whistler mode waves that modify the plasma in which they propagate have been seen, and the modification of the background medium caused the whistlers to become ducted (Stenzel, 1999). Among the many processes that generate whistler mode waves are instabilities in plasmas with anisotropic velocity distributions: loss cone instabilities give rise to whistlers when $T_{\perp}>T_{\|}$, and magnetic field aligned electron beams excite whistlers through Cherenkov resonances (Stenzel, 1999). We may speculate that when plasmoids interact with the surrounding magnetosheath plasma, and with its magnetic field, electric fields that are parallel to the magnetic field are set up at the plasmoid boundaries; that these electric fields accelerate electrons, forming beams; and that the beams, in turn, generate whistler mode waves.

The presence of whistler mode waves and waves in the lower hybrid frequency range is a property these plasmoids have. This does not exclude the possibility of such waves appearing in dynamic pressure pulses on spatial scales larger than the cross section of the magnetosphere that could therefore not be defined as plasmoids. Wave-induced diffusion plays a role in phenomena such as reconnection and impulsive penetration. In the latter process in particular, diffusion processes are needed to allow a plasmoid to pass from one magnetic environment to another - that is to say, from the magnetosheath into the magnetosphere. It is possible that the waves that are observed inside and at the boundaries of plasmoids constitute an essential part of the diffusion process that 
enables such structures to penetrate magnetic boundaries. It would therefore be of interest to measure the wave-induced diffusion in a plasmoid at the magnetopause. The requirement for such a measurement would be that both the electric field and plasma density could be resolved at the wave frequency. Such measurements were performed by Hurtig et al. (2004) in the laboratory and by Vaivads et al. (2004) in space. They were able to estimate the plasma density from the spacecraft potential, making use of an internal burst mode of the EFW instrument. The instrument is in its internal burst mode infrequently and only for short periods of time. The coincidence of an internal burst mode and a plasmoid observation at the magnetopause is therefore a rare occurrence, and none was found in the Cluster data from the month that was considered here.

Proton populations with temperatures of about $5 \mathrm{eV}$ are seen both deep in the magnetosphere and near the magnetopause. These observations are enabled by Alfvénic waves, which cause the cold ions to $\boldsymbol{E} \times \boldsymbol{B}$ drift at speeds above the threshold for detection by the ion spectrometer. Similar cold plasma populations that are $\boldsymbol{E} \times \boldsymbol{B}$ drifting have been seen before in the vicinity of the magnetopause (Sauvaud et al., 2001; McFadden et al., 2008). In the case presented here, density measurements by the Whisper instrument reveal that these ions are present throughout the region traversed by the spacecraft from geocentric distances of $5 R_{\mathrm{E}}$ to $10 R_{\mathrm{E}}$. The density is $2-4 \mathrm{~cm}^{-3}$, which is much lower than typical values for the plasmasphere and the plasmaspheric plumes (Darrouzet et al., 2008, 2009).

According to a statistical study by André and Cully (2012), the density, composition and continuous observation of this cold population suggest that it is a plasmaspheric wind - that is to say, a continuous flow of cold plasma escaping from the plasmasphere. The existence of the plasmaspheric wind had been predicted by Lemaire and Schunk (1992) and was confirmed by Dandouras (2013). Lysak et al. (1994) used an MHD model where a plane wave in the solar wind perturbed the magnetopause position leading to Alfvénic waves in the magnetosphere. Archer et al. (2013) showed that Pc5 oscillations in the magnetosphere can be caused by transient pulses that are shorter than the oscillation period. Archer et al. (2012) observed cold ions on the inside of the magnetopause and hypothesised that these observations were caused by plasmoids that later were seen by a different spacecraft in the magnetosheath a few $R_{\mathrm{E}}$ away. Our observation, by consistent particle and field measurements, of a fast $\boldsymbol{E} \times \boldsymbol{B}$ drifting cold ion population in the magnetosphere immediately after the plasmoid impact supports that picture of plasmoid interaction with the magnetosphere.

Waves are always present in the life of the plasmoids albeit on quite different scales. It has been found that the vast majority of the plasmoids observed in the magnetosheath can be generated at the bow shock, when it is rippled by MHD scale waves (Hietala and Plaschke, 2013). In the magnetosheath lower hybrid and whistler mode waves are seen in the plasmoids. When colliding with the magnetopause, plasmoids cause Alfvénic waves that propagate in the magnetosphere, and in plasma transport across the magnetopause wave-induced diffusion plays an important role.

\section{The Supplement related to this article is available online at doi:10.5194/angeo-32-991-2014-supplement.}

Acknowledgements. This work was supported by the Belgian Science Policy Office through the Solar-Terrestrial Centre of Excellence and by PRODEX/Cluster contract 13127/98/NL/VJ(IC)-PEA 90316. We thank P. M. E. Décréau for her kind help with the Whisper data analysis. We thank the Wind, and Cluster instrument teams, NASA CDAWeb, and the Cluster Active Archive for providing the data.

Topical Editor E. Roussos thanks E. Kronberg and one anonymous referee for their help in evaluating this paper.

\section{References}

Amata, E., Savin, S. P., Ambrosino, D., Bogdanova, Y. V., Marcucci, M. F., Romanov, S., and Skalsky, A.: High kinetic energy density jets in the Earth's magnetosheath: A case study, Planet Space Sci., 59, 482-494, doi:10.1016/j.pss.2010.07.021, 2011.

André, M. and Cully, C. M.: Low-energy ions: A previously hidden solar system particle population, Geophys. Res. Lett., 39, L03101, doi:10.1029/2011GL050242, 2012.

André, M., Behlke, R., Wahlund, J.-E., Vaivads, A., Eriksson, A.-I., Tjulin, A., Carozzi, T. D., Cully, C., Gustafsson, G., Sundkvist, D., Khotyaintsev, Y., Cornilleau-Wehrlin, N., Rezeau, L., Maksimovic, M., Lucek, E., Balogh, A., Dunlop, M., Lindqvist, P.-A., Mozer, F., Pedersen, A., and Fazakerley, A.: Multi-spacecraft observations of broadband waves near the lower hybrid frequency at the Earthward edge of the magnetopause, Ann. Geophys., 19, 1471-1481, doi:10.5194/angeo-19-1471-2001, 2001.

André, M., Vaivads, A., Khotyaintsev, Y. V., Laitinen, T., Nilsson, H., Stenberg, G., Fazakerley, A., and Trotignon, J. G.: Magnetic reconnection and cold plasma at the magnetopause, Geophys. Res. Lett., 37, L22108, doi:10.1029/2010GL044611, 2010.

Archer, M. O. and Horbury, T. S.: Magnetosheath dynamic pressure enhancements: occurrence and typical properties, Ann. Geophys., 31, 319-331, doi:10.5194/angeo-31-319-2013, 2013.

Archer, M. O., Horbury, T., and Eastwood, J.: Magnetosheath pressure pulses: Generation downstream of the bow shock from solar wind discontinuities, J. Geophys. Res., 117, A05228, doi:10.1029/2011JA017468, 2012.

Archer, M. O., Horbury, T. S., Eastwood, J. P., Weygand, J. M., and Yeoman, T. K.: Magnetospheric response to magnetosheath pressure pulses: A low-pass filter effect, J. Geophys. Res., 118, 5454-5466, doi:10.1002/jgra.50519, 2013.

Balogh, A., Carr, C. M., Acuña, M. H., Dunlop, M. W., Beek, T. J., Brown, P., Fornacon, K.-H., Georgescu, E., Glassmeier, K.H., Harris, J., Musmann, G., Oddy, T., and Schwingenschuh, K.: The Cluster Magnetic Field Investigation: overview of in-flight 
performance and initial results, Ann. Geophys., 19, 1207-1217, doi:10.5194/angeo-19-1207-2001, 2001.

Bostick, W. H.: Experimental Study of Ionized Matter Projected across a Magnetic Field, Physical Rev., 104, 292-299, doi:10.1103/PhysRev.104.292, 1956.

Brenning, N., Hurtig, T., and Raadu, M. A.: Conditions for plasmoid penetration across abrupt magnetic barriers, Phys. Plasmas, 12, 012309, doi:10.1063/1.1812277, 2005.

Cornilleau-Wehrlin, N., Chauveau, P., Louis, S., Meyer, A., Nappa, J. M., Perraut, S., Rezeau, L., Robert, P., Roux, A., de Villedary, C., de Conchy, Y., Friel, L., Harvey, C. C., Hubert, D., Lacombe, C., Manning, R., Wouters, F., Lefeuvre, F., Parrot, M., Pincon, J. L., Poirier, B., Kofman, W., and Louarn, P.: The Cluster SpatioTemporal Analysis of Field Fluctuations (STAFF) Experiment, Space Sci. Rev., 79, 107-136, doi:10.1023/A:1004979209565, 1997.

Dandouras, I.: Detection of a plasmaspheric wind in the Earth's magnetosphere by the Cluster spacecraft, Ann. Geophys., 31, 1143-1153, doi:10.5194/angeo-31-1143-2013, 2013.

Darrouzet, F., De Keyser, J., Décréau, P. M. E., El LemdaniMazouz, F., and Vallières, X.: Statistical analysis of plasmaspheric plumes with Cluster/WHISPER observations, Ann. Geophys., 26, 2403-2417, doi:10.5194/angeo-26-2403-2008, 2008.

Darrouzet, F., Gallagher, D. L., André, N., Carpenter, D. L., Dandouras, I., Décréau, P. M. E., De Keyser, J., Denton, R. E., Foster, J. C., Goldstein, J., Moldwin, M. B., Reinisch, B. W., Sandel, B. R., and Tu, J.: Plasmaspheric Density Structures and Dynamics: Properties Observed by the CLUSTER and IMAGE Missions, Space Sci. Rev., 145, 55-106, doi:10.1007/s11214-0089438-9, 2009.

De Keyser, J.: Linear magnetohydrodynamic response of the magnetopause to magnetosheath fluctuations, J. Geophys. Res., 105, 23167-23178, doi:10.1029/2000JA900083, 2000.

De Keyser, J. and Čadež, V.: Excitation of low-frequency fluctuations at the magnetopause by intermittent broadband magnetosheath waves, J. Geophys. Res., 106, 29467-29478, doi:10.1029/2001JA900078, 2001a.

De Keyser, J. and Čadež, V.: Transient development of magnetohydrodynamic wave mode conversion layers, J. Geophys. Res., 106, 15609-15620, doi:10.1029/2001JA900045, 2001b.

De Keyser, J., Roth, M., Reberac, F., Rezeau, L., and Belmont, G.: Resonant amplification of MHD waves in realistic subsolar magnetopause configurations, J. Geophys. Res., 104, 23992410, doi:10.1029/1998JA900060, 1999.

Décréau, P., Fergeau, P., Krannosels'kikh, V., Lévêque, M., Martin, P., Randriamboarison, O., Sené, F., Trotignon, J., Canu, P., and Mögensen, P.: Whisper, a resonance sounder and wave analyser: performances and perspective for the Cluster mission, Space Sci. Rev., 79, 157-193, doi:10.1023/A:1004931326404, 1997.

Décréau, P. M. E., Fergeau, P., Krasnoselskikh, V., Le Guirriec, E., Lévêque, M., Martin, Ph., Randriamboarison, O., Rauch, J. L., Sené, F. X., Séran, H. C., Trotignon, J. G., Canu, P., Cornilleau, N., de Féraudy, H., Alleyne, H., Yearby, K., Mögensen, P. B., Gustafsson, G., André, M., Gurnett, D. C., Darrouzet, F., Lemaire, J., Harvey, C. C., Travnicek, P., and Whisper experimenters (Table 1): Early results from the Whisper instrument on Cluster: an overview, Ann. Geophys., 19, 1241-1258, doi:10.5194/angeo-19-1241-2001, 2001.
Dmitriev, A. V. and Suvorova, A. V.: Traveling magnetopause distortion related to a large-scale magnetosheath plasma jet: THEMIS and ground-based observations, J. Geophys. Res., 117, A08217, doi:10.1029/2011JA016861, 2012.

Gekelman, W. and Pfister, H.: Experimental observations of the tearing of an electron current sheet, Phys. Fluids, 31, 2017-2025, doi:10.1063/1.866650, 1988.

Gunell, H., Hurtig, T., Nilsson, H., Koepke, M., and Brenning, N.: Simulations of a plasmoid penetrating a magnetic barrier, Plasma Phys. Control. Fusion, 50, 074013, doi:10.1088/07413335/50/7/074013, 2008.

Gunell, H., Walker, J. J., Koepke, M. E., Hurtig, T., Brenning, N., and Nilsson, H.: Numerical experiments on plasmoids entering a transverse magnetic field, Phys. Plasmas, 16, 112901, doi:10.1063/1.3267860, 2009.

Gunell, H., Nilsson, H., Stenberg, G., Hamrin, M., Karlsson, T., Maggiolo, R., André, M., Lundin, R., and Dandouras, I.: Plasma penetration of the dayside magnetopause, Phys. Plasmas, 19, 072906, doi:10.1063/1.4739446, 2012.

Gustafsson, G., André, M., Carozzi, T., Eriksson, A. I., Fälthammar, C.-G., Grard, R., Holmgren, G., Holtet, J. A., Ivchenko, N., Karlsson, T., Khotyaintsev, Y., Klimov, S., Laakso, H., Lindqvist, P.-A., Lybekk, B., Marklund, G., Mozer, F., Mursula, K., Pedersen, A., Popielawska, B., Savin, S., Stasiewicz, K., Tanskanen, P., Vaivads, A., and Wahlund, J.-E.: First results of electric field and density observations by Cluster EFW based on initial months of operation, Ann. Geophys., 19, 1219-1240, doi:10.5194/angeo19-1219-2001, 2001.

Hietala, H. and Plaschke, F.: On the generation of magnetosheath high speed jets by bow shock ripples, J. Geophys. Res., 118, 7237-7245, doi:10.1002/2013JA019172, 2013.

Hietala, H., Laitinen, T. V., Andréeová, K., Vainio, R., Vaivads, A., Palmroth, M., Pulkkinen, T. I., Koskinen, H. E. J., Lucek, E. A., and Rème, H.: Supermagnetosonic Jets behind a Collisionless Quasiparallel Shock, Phys. Rev. Lett., 103, 245001, doi:10.1103/PhysRevLett.103.245001, 2009.

Hietala, H., Partamies, N., Laitinen, T. V., Clausen, L. B. N., Facskó, G., Vaivads, A., Koskinen, H. E. J., Dandouras, I., Rème, H., and Lucek, E. A.: Supermagnetosonic subsolar magnetosheath jets and their effects: from the solar wind to the ionospheric convection, Ann. Geophys., 30, 33-48, doi:10.5194/angeo-30-33-2012, 2012.

Hurtig, T., Brenning, N., and Raadu, M. A.: The penetration of plasma clouds across magnetic boundaries: The role of high frequency oscillations, Phys. Plasmas, 11, L33-L36, doi:10.1063/1.1753575, 2004.

Hurtig, T., Brenning, N., and Raadu, M. A.: The role of high frequency oscillations in the penetration of plasma clouds across magnetic boundaries, Phys. Plasmas, 12, 012308, doi:10.1063/1.1812276, 2005.

Johnstone, A. D., Alsop, C., Burge, S., Carter, P. J., Coates, A. J., Coker, A. J., Fazakerley, A. N., Grande, M., Gowen, R. A., Gurgiolo, C., Hancock, B. K., Narheim, B., Preece, A., Sheather, P. H., Winningham, J. D., and Woodliffe, R. D.: Peace: a Plasma Electron and Current Experiment, Space Sci. Rev., 79, 351-398, doi:10.1023/A:1004938001388, 1997.

Karlsson, T., Brenning, N., Nilsson, H., Trotignon, J.-G., Vallières, X., and Facsko, G.: Localized density enhancements in the magnetosheath; 3D morphology and possible impor- 
tance for impulsive penetration, J. Geophys. Res., 117, A03227, doi:10.1029/2011JA017059, 2012.

Lemaire, J.: Impulsive penetration of filamentary plasma elements into the magnetospheres of the earth and Jupiter, Planet. Space Sci., 25, 887-890, doi:10.1016/0032-0633(77)90042-3, 1977.

Lemaire, J. and Schunk, R. W.: Plasmaspheric wind, J. Atmos. Terr. Phys., 54, 467-477, doi:10.1016/0021-9169(92)90026-H, 1992.

Lysak, R. L., Song, Y., and Lee, D.-H.: Generation of ULF waves by fluctuations in the magnetopause position, Washington DC American Geophysical Union Geophysical Monograph Series, 81, 273-281, doi:10.1029/GM081p0273, 1994.

McFadden, J. P., Carlson, C. W., Larson, D., Bonnell, J., Mozer, F. S., Angelopoulos, V., Glassmeier, K.-H., and Auster, U.: Structure of plasmaspheric plumes and their participation in magnetopause reconnection: First results from THEMIS, Geophys. Res. Lett., 35, L17S10, doi:10.1029/2008GL033677, 2008.

Němeček, Z., Šafránková, J., Přech, L., Sibeck, D. G., Kokubun, S., and Mukai, T.: Transient flux enhancements in the magnetosheath, Geophys. Res. Lett., 25, 1273-1276, doi:10.1029/98GL50873, 1998.

Plaschke, F., Angelopoulos, V., and Glassmeier, K.-H.: Magnetopause surface waves: THEMIS observations compared to MHD theory, J. Geophys. Res., 118, 1483-1499, doi:10.1002/jgra.50147, 2013a.

Plaschke, F., Hietala, H., and Angelopoulos, V.: Anti-sunward highspeed jets in the subsolar magnetosheath, Ann. Geophys., 31, 1877-1889, doi:10.5194/angeo-31-1877-2013, 2013b.

Plechaty, C., R. Presura, R., and Esaulov, A. A.: Focusing of an Explosive Plasma Expansion in a Transverse Magnetic Field, Phys. Rev. Lett., 111, 185002, doi:10.1103/PhysRevLett.111.185002, 2013

Rème, H., Aoustin, C., Bosqued, J. M., Dandouras, I., Lavraud, B., Sauvaud, J. A., Barthe, A., Bouyssou, J., Camus, Th., Coeur-Joly, O., Cros, A., Cuvilo, J., Ducay, F., Garbarowitz, Y., Medale, J. L., Penou, E., Perrier, H., Romefort, D., Rouzaud, J., Vallat, C., Alcaydé, D., Jacquey, C., Mazelle, C., d’Uston, C., Möbius, E., Kistler, L. M., Crocker, K., Granoff, M., Mouikis, C., Popecki, M., Vosbury, M., Klecker, B., Hovestadt, D., Kucharek, H., Kuenneth, E., Paschmann, G., Scholer, M., Sckopke, N., Seidenschwang, E., Carlson, C. W., Curtis, D. W., Ingraham, C., Lin, R. P., McFadden, J. P., Parks, G. K., Phan, T., Formisano, V., Amata, E., Bavassano-Cattaneo, M. B., Baldetti, P., Bruno, R., Chionchio, G., Di Lellis, A., Marcucci, M. F., Pallocchia, G., Korth, A., Daly, P. W., Graeve, B., Rosenbauer, H., Vasyliunas, V., McCarthy, M., Wilber, M., Eliasson, L., Lundin, R., Olsen, S., Shelley, E. G., Fuselier, S., Ghielmetti, A. G., Lennartsson, W., Escoubet, C. P., Balsiger, H., Friedel, R., Cao, J.-B., Kovrazhkin, R. A., Papamastorakis, I., Pellat, R., Scudder, J., and Sonnerup, B.: First multispacecraft ion measurements in and near the Earth's magnetosphere with the identical Cluster ion spectrometry (CIS) experiment, Ann. Geophys., 19, 1303-1354, doi:10.5194/angeo19-1303-2001, 2001.

Santolík, O., M. Parrot, M., and Lefeuvre, F.: Singular value decomposition methods for wave propagation analysis, Radio Sci., 38, 1010, doi:10.1029/2000RS002523, 2003.

Sauvaud, J.-A., Lundin, R., Rème, H., McFadden, J. P., Carlson, C., Parks, G. K., Möbius, E., Kistler, L. M., Klecker, B., Amata, E., DiLellis, A. M., Formisano, V., Bosqued, J. M., Dandouras, I., Décréau, P., Dunlop, M., Eliasson, L., Korth, A., Lavraud,
B., and McCarthy, M.: Intermittent thermal plasma acceleration linked to sporadic motions of the magnetopause, first Cluster results, Ann. Geophys., 19, 1523-1532, doi:10.5194/angeo-191523-2001, 2001.

Savin, S., Zelenyi, L., Amata, E., Buechner, J., Blecki, J., Greco, A., Klimov, S., Lopez, R. E., Nikutowski, B., Panov, E., Pickett, J., Rauch, J. L., Romanov, S., Song, P., Skalsky, A., Smirnov, V., Taktakishvili, A., Veltry, P., and Zimbardo, G.: Magnetosheath interaction with high latitude magnetopause: Dynamic flow chaotization, Planet. Space Sci., 53, 133-140, doi:10.1016/j.pss.2004.09.037, 2005.

Savin, S., Amata, E., Zelenyi, L., Budaev, V., Consolini, G., Treumann, R., Lucek, E., Safrankova, J., Nemecek, Z., Khotyaintsev, Y., Andre, M., Buechner, J., Alleyne, H., Song, P., Blecki, J., Rauch, J. L., Romanov, S., Klimov, S., and Skalsky, A.: High energy jets in the Earth's magnetosheath: Implications for plasma dynamics and anomalous transport, JETP Lett., 87, 593-599, doi:10.1134/S0021364008110015, 2008.

Savin, S., Budaev, V., Zelenyi, L., Amata, E., Sibeck, D., Lutsenko, V., Borodkova, N., Zhang, H., Angelopoulos, V., Safrankova, J., Nemecek, Z., Blecki, J., Buechner, J., Kozak, L., Romanov, S., Skalsky, A., and Krasnoselskikh, V.: Anomalous interaction of a plasma flow with the boundary layers of a geomagnetic trap, JETP Letters, 93, 754-762, doi:10.1134/S0021364011120137, 2011.

Savin, S., Amata, E., Zelenyi, L., Lutsenko, V., Safrankova, J., Nemecek, Z., Borodkova, N., Buechner, J., Daly, P. W., Kronberg, E. A., Blecki, J., Budaev, V., Kozak, L., Skalsky, A., and Lezhen, L.: Super fast plasma streams as drivers of transient and anomalous magnetospheric dynamics, Ann. Geophys., 30, 1-7, doi:10.5194/angeo-30-1-2012, 2012.

Savin, S., Amata, E., Budaev, V., Zelenyi, L., Kronberg, E. A., Buechner, J., Safrankova, J., Nemecek, Z., Blecki, J., Kozak, L., Klimov, S., Skalsky, A., and Lezhen, L.: On nonlinear cascades and resonances in the outer magnetosphere, JETP Letters, 99, 16-21, doi:10.1134/S002136401401010X, 2014.

Schmidt, G.: Plasma Motion Across Magnetic Fields, Phys. Fluids, 3, 961-965, 1960.

Shue, J., Chao, J. K., Fu, H. C., Russell, C. T., Song, P., Khurana, K. K., and Singer, H. J.: A new functional form to study the solar wind control of the magnetopause size and shape, J. Geophys. Res., 102, 9497-9512, doi:10.1029/97JA00196, 1997.

Shue, J.-H. and Chao, J.-K.: The role of enhanced thermal pressure in the earthward motion of the Earth's magnetopause, J. Geophys. Res., 118, 3017-3026, doi:10.1002/jgra.50290, 2013.

Shue, J.-H., Chao, J.-K., Song, P., McFadden, J. P., Suvorova, A., Angelopoulos, V., Glassmeier, K. H., and Plaschke, F.: Anomalous magnetosheath flows and distorted subsolar magnetopause for radial interplanetary magnetic fields, Geophys. Res. Lett., 36, L18112, doi:10.1029/2009GL039842, 2009.

Simpson, J. and Weiner, E. (Eds.): The Oxford English Dictionary, Oxford University Press, Oxford, 2nd Edn., 1989.

Stenberg, G., Oscarsson, T., André, M., Vaivads, A., BackrudIvgren, M., Khotyaintsev, Y., Rosenqvist, L., Sahraoui, F., Cornilleau-Wehrlin, N., Fazakerley, A., Lundin, R., and Décréau, P. M. E.: Internal structure and spatial dimensions of whistler wave regions in the magnetopause boundary layer, Ann. Geophys., 25, 2439-2451, doi:10.5194/angeo-25-2439-2007, 2007. 
Stenzel, R. L.: Whistler waves in space and laboratory plasmas, J. Geophys. Res., 104, 14379-14395, doi:10.1029/1998JA900120, 1999.

Stenzel, R. L., Urrutia, J. M., and Strohmaier, K. D.: Nonlinear electron magnetohydrodynamics physics. I. Whistler spheromaks, mirrors, and field reversed configurations, Phys. Plasmas, 15, 042307, doi:10.1063/1.2903065, 2008.

Tenerani, A., Contel, O. L., Califano, F., Robert, P., Fontaine, D., Cornilleau-Wehrlin, N., and Sauvaud, J.-A.: Cluster observations of whistler waves correlated with ion-scale magnetic structures during the 17 August 2003 substorm event, J. Geophys. Res., 118, 6072-6089, doi:10.1002/jgra.50562, 2013.

Thuecks, D. J., Skiff, F., and Kletzing, C. A.: Measurements of parallel electron velocity distributions using whistler wave absorption, Rev. Sci. Instrum., 83, 083503, doi:10.1063/1.4742766, 2012.
Vaivads, A., André, M., Buchert, S. C., Wahlund, J.-E., Fazakerley, A. N., and Cornilleau-Wehrlin, N.: Cluster observations of lower hybrid turbulence within thin layers at the magnetopause, Geophys. Res. Lett., 31, L03804, doi:10.1029/2003GL018142, 2004.

Watt, C. E. J., Degeling, A. W., and Rankin, R.: Constructing the frequency and wave normal distribution of whistlermode wave power, J. Geophys. Res., 118, 1984-1991, doi:10.1002/jgra.50231, 2013.

Wessel, F. J., Hong, R., Song, J., Fisher, A., Rostoker, N., Ron, A., Li, R., and Fan, R. Y.: Plasmoid propagation in a transverse magnetic field and in a magnetized plasma, Phys. Fluids, 31, 37783784, doi:10.1063/1.866897, 1988. 